\title{
Assessing Binary Mixture Effects from Genotoxic and Endocrine Disrupting Environmental Contaminants Using Infrared Spectroscopy
}

\author{
Camilo L. M. Morais, ${ }^{\dagger}$ Richard F. Shore, $^{\ddagger}$ M. Glória Pereira, ${ }^{\ddagger}$ and Francis L. Martin ${ }^{*} \dagger \oplus$ \\ ${ }^{\dagger}$ School of Pharmacy and Biomedical Sciences, University of Central Lancashire (UCLan), Preston PR1 2HE, U.K. \\ ${ }^{\ddagger}$ Centre of Ecology \& Hydrology, Lancaster Environment Centre, Lancaster LA1 4AP, U.K.
}

Supporting Information

ABSTRACT: Benzo $[a]$ pyrene $(\mathrm{B}[a] \mathrm{P})$, polychlorinated biphenyls (PCBs), and polybrominated diphenyl ethers (PBDEs) are persistent contaminants and concern has arisen over co-exposure of organisms when the chemicals exist in mixtures. Herein, attenuated total reflection Fourier transform infrared spectroscopy was used to identify biochemical alterations induced in cells by single and binary mixtures of these environmental chemicals. It was also investigated as a method to identify if interactions are occurring in mixtures and as a possible tool to predict mixture effects. Mallard fibroblasts were treated with single and binary mixtures of $\mathrm{B}[a] \mathrm{P}, \mathrm{PCB} 126, \mathrm{PCB} 153, \mathrm{BDE} 47$, and BDE209. Comparison of observed spectra from cells treated with binary mixtures with expected additive spectra, which were created from individual exposure spectra, indicated that in many areas of the spectrum, less-than-additive binary mixture effects may occur. However, possible greater-than-additive alterations were identified in the $1650-1750 \mathrm{~cm}^{-1}$ lipid region and may demonstrate a common mechanism of $\mathrm{B}[\mathrm{a}] \mathrm{P}$ and $\mathrm{PCBs}$ or PBDEs, which can enhance toxicity in mixtures.

\section{INTRODUCTION}

There are many types of chemical contaminants that find their way into environmental compartments during their usage cycle or through accidental release. The past century has seen an increasing awareness of the potential risk such chemicals pose to the health of ecosystems and environmental organisms. Some pollutants are extremely persistent and bioaccumulate up food chains, giving rise to concern for top-level predators, such as predatory bird species. ${ }^{1}$ Benzo $[a]$ pyrene $(\mathrm{B}[a] \mathrm{P})$ is an example of a pervasive polycyclic aromatic hydrocarbon (PAH) contaminant that is abundantly found in the environment due to anthropogenic activity associated with partial combustion. $\mathrm{B}[a] \mathrm{P}$ exposure has been largely associated with inhalation of cigarette smoke, car exhaust, and industrial air pollution as well as via dietary intake. ${ }^{2,3}$ Exposure to $\mathrm{B}[a] \mathrm{P}$ and other PAHs is considered a risk to humans and wildlife due to reported carcinogenic toxicity. $\mathrm{B}[a] \mathrm{P}$ can bind to the aryl hydrocarbon receptor (AhR) and mediate the expression of cytochrome P450 enzymes, including CYP1A1, which metabolizes the chemical into its DNA binding, mutagenic form. ${ }^{4,5}$ Other highly persistent chemicals include polychlorinated biphenyls (PCBs) and polybrominated diphenyl ethers (PBDEs), some congeners of which are also reported to possess AhR-binding abilities like $\mathrm{B}[a] \mathrm{P} .^{6,7}$ PCBs and PBDEs have been used as additives in various consumer products, such

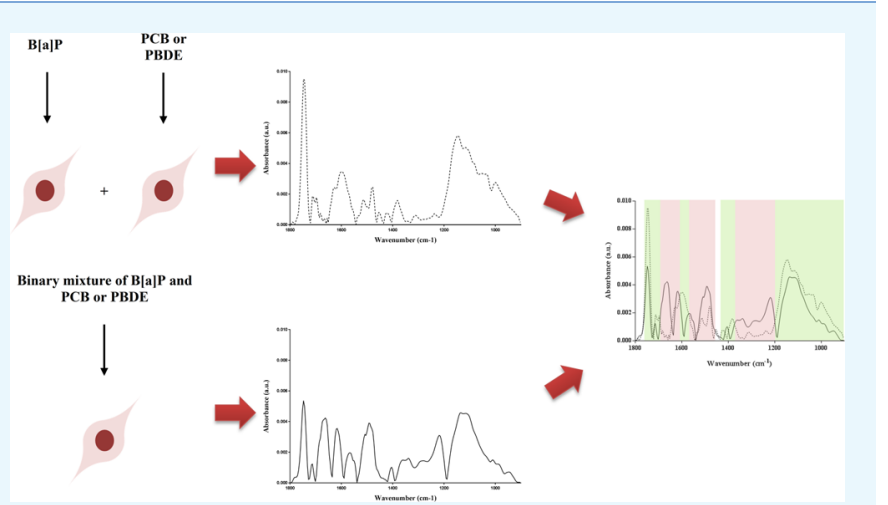

as paints, textiles, and electronics, to act as coolants and flame retardants. 8 They have been found to exert toxicity on a number of biological systems, including the endocrine, immune, and nervous systems. ${ }^{9,10}$ Although PCBs and many PBDE congeners are now banned in the EU and other locations, they are still currently found in environmental matrices due to their persistent nature and are presently used in some developing countries. ${ }^{11-13}$

The concern related to these contaminants is not only due to their potential toxicities, but also due to the possibility that they exist as part of mixtures. Chemicals are often considered in isolation, but in reality, organisms in the environment are simultaneously and sequentially exposed to a wide range of contaminants, many of which have different toxic mechanisms. It is commonly assumed that the toxicity of a mixture can be predicted by adding the toxicities of the mixture components together, in what is known as an additive model of mixture effects. ${ }^{14,15}$ Although this leads to accurate mixture toxicity predictions in most instances, interactions may occur at the biological target sites or between chemicals, which can cause unexpected mixture toxicity. Interactions can lead to two

Received: August 6, 2018

Accepted: October 4, 2018

Published: October 17, 2018 
A

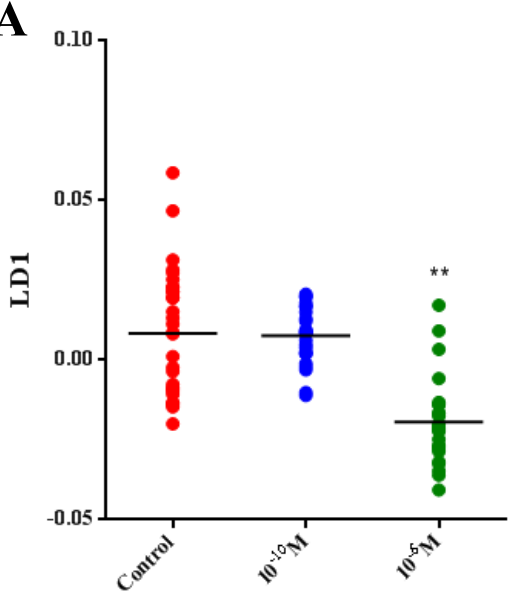

Concentration (M)

B

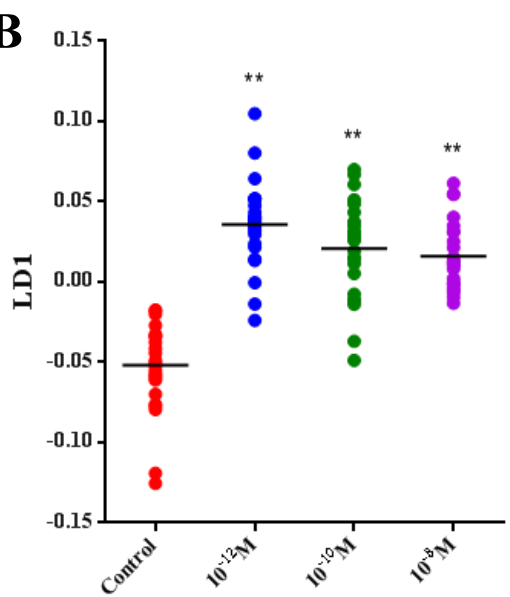

Concentration (M)

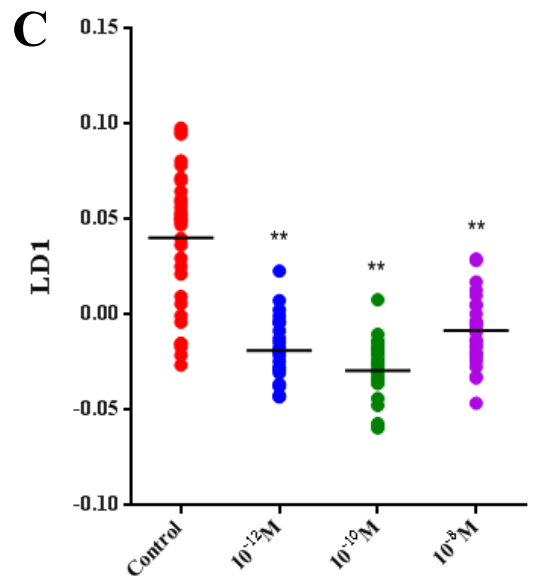

Concentration (M)
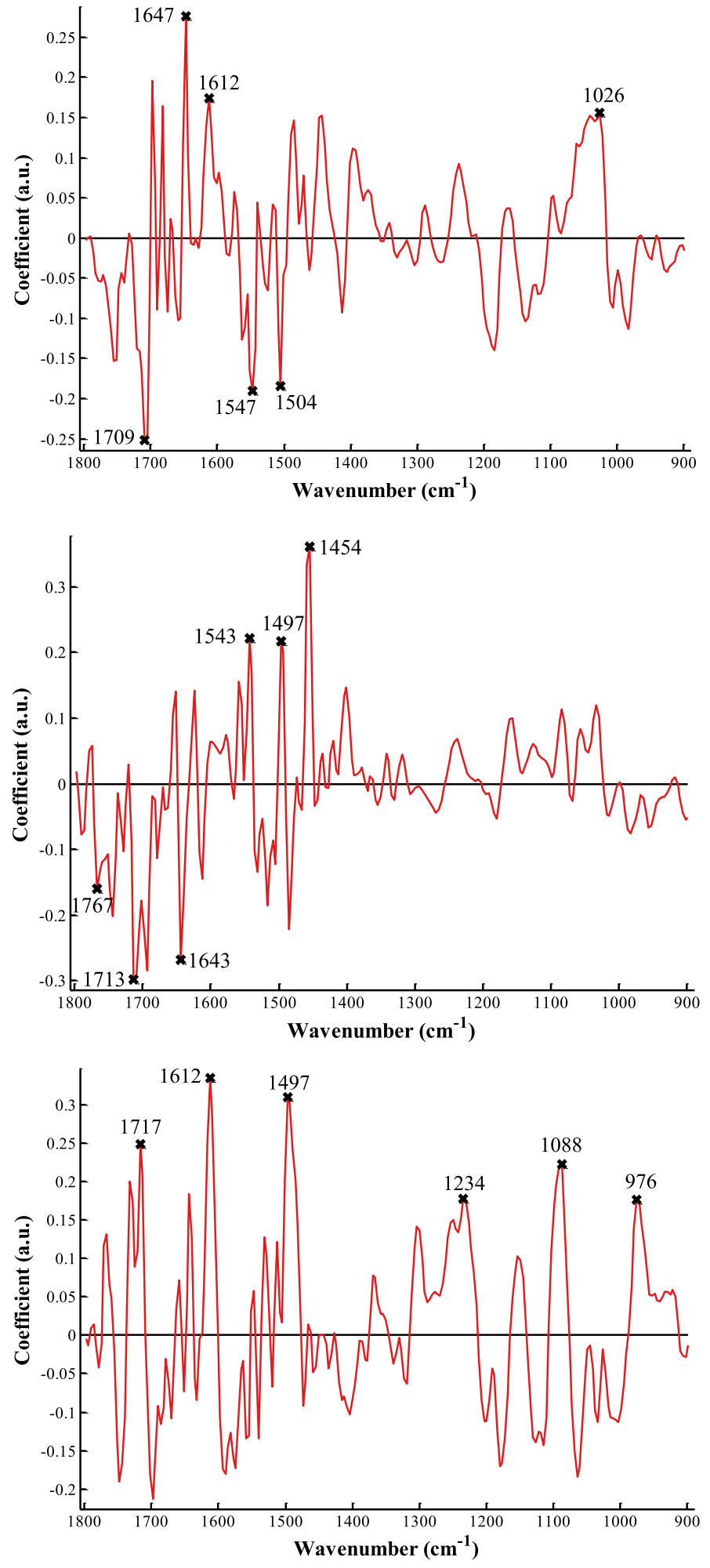

Figure 1. PCA-LDA scores plots and corresponding LD1 loadings plots with the top six wavenumbers highlighted from mallard cells treated with $\mathrm{B}[a] \mathrm{P}, \mathrm{BDE} 47$ and BDE209. Significance from control calculated using one-way ANOVA followed by Dunnett's post-hoc test $[P<0.05$ level $(*)$ or $P<0.01$ level (**)]. Mallard cells treated with (A) $10^{-6}$ and $10^{-10} \mathrm{M} \mathrm{B}[\mathrm{a}] \mathrm{P}$; (B) $10^{-8} \mathrm{M}, 10^{-10} \mathrm{M}$, and $10^{-12} \mathrm{M} \mathrm{BDE} 47$; and (C) $10^{-8} \mathrm{M}$, $10^{-10}$ $\mathrm{M}$, and $10^{-12} \mathrm{M}$ PBDE209.

possible outcomes, a reduction in expected toxicity (antagonism) or a greater-than-expected toxicity (synergism). ${ }^{16}$ The additive approach is used for the majority of regulatory assessments regarding mixtures, meaning that environmental organisms may be left vulnerable to the effects of interactive mixture effects. ${ }^{17}$ It is not practically possible to test every single mixture that may occur in the wider environment, and as some chemicals are not being actively released, they may not be incorporated into risk assessments. $\mathrm{B}[a] \mathrm{P}$ along with $\mathrm{PCBs}$ and PBDEs are extremely abundant contaminants and 
therefore are highly likely to occur together in mixtures. They also have at least one common toxicity pathway, which may allow for interactions to arise. The possibility that synergy in mixtures, especially those including legacy contaminants, may go undetected is concerning. Therefore, we need to have efficient techniques to test for interactions in mixtures that can be used to guide risk assessments.

Most of cell properties standard determinations are made by staining methodologies; ${ }^{18}$ confocal laser scanning microscopes equipped with photobleaching protocols; ${ }^{19}$ flow cytometry; ${ }^{20}$ and classical methods of fresh and dry cell density determinations. ${ }^{21-23}$ However, as a main disadvantage, most of these methodologies suffer from being highly timeconsuming. ${ }^{24}$ For screening of genotoxicity and oestrogenicity of endocrine disrupting chemicals, molecular biochemical methodologies are gold standard, ${ }^{25}$ including E-SCREEN assay, ${ }^{26}$ MVLN assay, ${ }^{25}$ and yeast estrogen screen (YES) assay, ${ }^{27}$ among others. ${ }^{25,28-30}$ Endocrine disrupting chemicals have also been measured by modern analytical instrumental techniques, for example, by using gas chromatography coupled with mass spectrometry (GC-MS), ${ }^{31-33}$ liquid chromatography coupled with mass spectrometry (LC-MS), ${ }^{34}$ and ultraperformance liquid chromatography coupled with mass spectrometry (UPLC-MS). ${ }^{33,35}$ In addition, many other cell properties have been investigated by atomic force microscopy, ${ }^{36}$ such as the influence of air drying and fixation on the morphology and viscoelasticity of cells, ${ }^{37}$ probing of cell mechanics, ${ }^{38}$ and cell elasticity. ${ }^{39}$

Vibrational spectroscopy techniques have proved to be valuable exploratory tools for various, diverse experimental purposes, including cancer research, ${ }^{40,41}$ environmental monitoring, $^{42,43}$ and quality assurance. ${ }^{43,44}$ These techniques offer a number of advantages such as being cost-effective, nondestructive to samples, and high throughput. Vibrational spectroscopy can be used to create a biochemical profile of samples by measuring the absorption of light and changes in vibrational energy levels. ${ }^{45}$ Two main vibrational spectroscopy techniques have been used significantly in biochemical-related applications: Raman and infrared (IR) spectroscopy. ${ }^{46-49}$ The first one, based on Raman scattering effect, has found many applications, including hyperspectral imaging of single cells, ${ }^{50}$ detection of biological molecules and environmental contaminants, ${ }^{51}$ identification of spatial and cellular changes, ${ }^{52}$ and detection of PCB and PBDE compounds. ${ }^{53,54}$ Attenuated total reflection Fourier transform infrared (ATR-FTIR) spectroscopy is a specific type of vibrational spectroscopy where the sample of choice is interrogated with polychromatic IR light, which is reflected within an internal reflective element (IRE). ${ }^{55}$ Biochemical bonds absorb photons at specific characteristic wavelengths depending on the frequency required for bonds to vibrate and have a change in dipole moment. The output from this is a spectrum showing the absorbance of infrared light at each of the measured wavelengths, which characterizes the molecular composition of the sample and can be used to infer structural and functional information. ${ }^{55}$ Previously, ATR-FTIR spectroscopy has been used for environmental monitoring ${ }^{42}$ and to study the effects of environmentally relevant chemicals in cells and tissues. ${ }^{56,57}$ This has led to consideration of the technique as a tool to analyze the biological effects of chemical mixtures. Similarly, other types of IR spectroscopy have been used as a powerful tool for many types of cell investigations. ${ }^{58,59}$ In this study, we aim to assess ATR-FTIR spectra in this capacity by using it to characterize the cellular effects of exposure to single contaminants as well as binary mixtures of $\mathrm{B}[a] \mathrm{P}$ with $\mathrm{PCB}$ or $\mathrm{PBDE}$ congeners in avian fibroblast cells. We also aim to determine whether IR spectroscopy can be used to identify when a binary mixture of dissimilarly acting agents leads to nonadditive mixture effects and whether the effects of mixtures can be predicted by creating expected spectra from cells treated with the individual component chemicals. In this manner, ATR-FTIR spectroscopy may represent a complementary tool to quickly and cheaply analyze the effects of binary pairs of environmental pollutants, either as a screening tool before further analysis or to reduce the scale of mixture experiments by using single exposure data.

\section{RESULTS AND DISCUSSION}

Biochemical Alterations Induced by Contaminants. To verify if ATR-FTIR spectroscopy can be used as a tool to study mixtures, it was first established whether the technique could identify biochemical alterations associated with dose and treatment exposures. For visualization, spectra were processed using PCA-LDA (10 PCs, 97\% explained variance) to produce one-dimensional (1D) scores plots that illustrate treatmentinduced separation from control along with corresponding loading plots to show biochemical alterations responsible for the separation. Tentative wavenumber alterations were assigned using spectral interpretations from Movasaghi et al. ${ }^{60}$ Loading plots along linear discriminant 1 (LD1) from $\mathrm{B}[a]$ P-treated mallard fibroblasts (Figure $1 \mathrm{~A}$, see Supporting Information (SI) Table S1) showed that the top six wavenumber-associated alterations induced by $\mathrm{B}[a] \mathrm{P}$ were seen in molecular functional groups found in lipids $(\mathrm{C}=\mathrm{O}$ stretching in esters, $\left.1709 \mathrm{~cm}^{-1}\right)$, amide $\mathrm{I}(\mathrm{C}=\mathrm{O}$ stretching weakly coupled to $\mathrm{C}-\mathrm{N}$ stretching and $\mathrm{N}-\mathrm{H}$ in-plane bending, 1647 and $\left.1612 \mathrm{~cm}^{-1}\right)$, amide II (C-N stretching and $\mathrm{C}-\mathrm{N}-\mathrm{H}$ bending weakly coupled to $\mathrm{C}=\mathrm{O}$ stretching, 1547 and $\left.1504 \mathrm{~cm}^{-1}\right)$, and glycogen ( $\mathrm{C}-\mathrm{O}$ stretching in $-\mathrm{CH}_{2} \mathrm{OH}, 1026 \mathrm{~cm}^{-1}$ ) regions. As $\mathrm{B}[\mathrm{a}] \mathrm{P}$ is reported to be a genotoxin and potential carcinogen, some DNA alterations $\left(\mathrm{PO}_{2}{ }^{-}\right.$symmetric and asymmetric stretchings) were expected. The loadings show that there are peaks in the DNA region (ca. $\left.970-1250 \mathrm{~cm}^{-1}\right)$, indicating that alterations are occurring there; however, other alterations outweigh those in magnitude. This indicates that alterations associated with different mechanisms of toxicity, or possibly those downstream of interactions with DNA, are affecting cells to a greater extent. It has been shown that in its parent form, $\mathrm{B}[a] \mathrm{P}$ can also cause toxicity via nongenotoxic pathways. ${ }^{61}$

The sensitivities and specificities of the PCA-LDA model to differentiate cells exposure to different concentration levels of $\mathrm{B}[a] \mathrm{P}$ are depicted in Table 1 . Cells treated with $\mathrm{B}[a] \mathrm{P} 10^{-6}$ $\mathrm{M}$ (highest concentration) have a sensitivity of $80 \%$, indicating that this group is very distinct from the others. Hockley et al. reported concentrations as low as $10^{-7} \mathrm{M} \mathrm{B}[a] \mathrm{P}$ to alter MCF7 and HepG2 cells. ${ }^{62}$ However, for control cells and cells exposed to a small concentration of $\mathrm{B}[a] \mathrm{P}\left(10^{-10} \mathrm{M}\right)$, the sensitivity values are low (60-69\%), indicating similarities between these two groups.

The toxicity of $\mathrm{B}[a] \mathrm{P}$ is known to be dependent on a number of factors, including cell type, as the expression of CYP isoforms is necessary to metabolize it to a pro-carcinogenic, DNA-binding form. ${ }^{62}$ Fewer DNA alterations than expected may be seen in mallard cells due to differential expression of CYP1A1 or differences in the AhR receptor, which needs to be bound to instigate downstream responses leading to the 
Table 1. Sensitivity and Specificity Based on PCA-LDA for Comparing Different Concentration Levels of Contaminants on Mallard Cells

\begin{tabular}{|c|c|c|c|}
\hline contaminant & concentration level (M) & sensitivity (\%) & specificity (\%) \\
\hline \multirow[t]{3}{*}{$\mathrm{B}[a] \mathrm{P}$} & control & 69 & 90 \\
\hline & $10^{-10}$ & 60 & 90 \\
\hline & $10^{-6}$ & 80 & 75 \\
\hline \multirow[t]{4}{*}{ BDE47 } & control & 97 & 96 \\
\hline & $10^{-12}$ & 44 & 85 \\
\hline & $10^{-10}$ & 28 & 78 \\
\hline & $10^{-8}$ & 40 & 85 \\
\hline \multirow[t]{4}{*}{ BDE209 } & control & 66 & 97 \\
\hline & $10^{-12}$ & 52 & 85 \\
\hline & $10^{-10}$ & 52 & 78 \\
\hline & $10^{-8}$ & 80 & 92 \\
\hline \multirow[t]{4}{*}{ PCB 153} & control & 57 & 79 \\
\hline & $10^{-12}$ & 20 & 85 \\
\hline & $10^{-10}$ & 60 & 84 \\
\hline & $10^{-8}$ & 44 & 81 \\
\hline \multirow[t]{4}{*}{ PCB126 } & control & 71 & 89 \\
\hline & $10^{-12}$ & 56 & 88 \\
\hline & $10^{-10}$ & 48 & 88 \\
\hline & $10^{-8}$ & 72 & 85 \\
\hline
\end{tabular}

expression of CYP enzymes. ${ }^{63}$ Although overall results were not significant, Western blot analysis (see SI Table S7) does appear to show a reduction in CYP1A1 expression in comparison to data available from MCF-7 cells (not presented here), which may explain this. As well as genotoxic mechanisms, some metabolic intermediates of $\mathrm{B}[a] \mathrm{P}$ have redox cycling capabilities that can cause oxidative stress. ${ }^{64}$ This may explain alterations seen in lipids and proteins due to damage by ROS as well as subsequent instigation of protein and carbohydrate remodeling pathways. ${ }^{62,65}$

ATR-FTIR spectroscopy was able to detect different alteration profiles in cells exposed to PBDE congeners 47 and 209 (Figure 1B,C). The PCA-LDA model (10 PCs, 98\% explained variance) shows high sensitivity (97\%) and specificity (96\%) for control cells, indicating that this group is distinguished from the others (treated cells) (Table 1). Within the treated cells groups, the sensitivities values are considerably low $(28-44 \%)$, showing that the effect of concentration variation did not influence cell alterations. The six largest alterations in BDE47-treated mallard cells (Figure $1 \mathrm{~B}$, see SI Table S2) largely reflected protein biomolecule alterations including $\mathrm{C}=\mathrm{O}$ stretching in amide $\mathrm{I}\left(1643 \mathrm{~cm}^{-1}\right)$, amide II $\left(1543 \mathrm{~cm}^{-1} ; 1497 \mathrm{~cm}^{-1}\right)$, and methyl groups (asymmetric $\mathrm{C}-\mathrm{H}$ deformation, $1454 \mathrm{~cm}^{-1}$ ) as well as some fatty acid lipid alterations ( $\mathrm{C}=\mathrm{O}$ stretching in carboxylic acid, 1767 and $1713 \mathrm{~cm}^{-1}$ ). Score and loading plots from mallard cells treated with BDE209 (Figure 1C, see SI Table S3) also highlight extensive protein alterations. Exposure is also associated with amide I $\left(1612 \mathrm{~cm}^{-1}\right)$, amide II $\left(1497 \mathrm{~cm}^{-1}\right)$, and amide III ( $\mathrm{C}-\mathrm{N}$ stretching and $\mathrm{N}-\mathrm{H}$ in-plane bending with contributions of $\mathrm{CH}_{2}$ wagging vibrations, $1237 \mathrm{~cm}^{-1}$ ) changes as well as lipid $\left(1717 \mathrm{~cm}^{-1}\right)$ and DNA (symmetric $\mathrm{PO}_{2}^{-}$stretching, 1088 and $976 \mathrm{~cm}^{-1}$ ) alterations. Although the toxicities of PBDE congeners such as 47 and 209 have been comparatively well studied in whole tissues or organisms, ${ }^{66}$ there is less information on the underlying toxic cellular effects. It has been shown that both these congeners, particularly $\mathrm{BDE} 47$, have neurological and developmental toxicity, which is thought to be caused by contaminant-induced oxidative stress. Generation of ROS can occur even at low contaminant concentrations and lead to sublethal effects such as damage to protein secondary structure and lipids. ${ }^{67}$ BDE209 also induced DNA alterations in the mallard cells (Figure 1C). For this compound, the PCA-LDA model (10 PCs, 97\% explained variance) presented high sensitivity (80\%) and specificity (92\%) for cells treated with $10^{-8}$ M BDE209 (Table 1), showing that this group is very different from the others. Control cells did not differentiate well from cells treated with $10^{-12} \mathrm{M}$ and $10^{-10} \mathrm{M}$ BDE209, where a sensitivity of $66 \%$ was found. BDE209 is a much larger congener and has been associated with carcinogenic effects. It has been found to cause DNA damage via oxidative stress-related pathways, but it may also be able to induce epigenetic changes as well. ${ }^{68,69}$

Similar to the toxicity of PBDEs, PCBs can cause neurotoxicity, endocrine disruption, and potentially carcinogenic changes depending on the congener involved. The position of chlorine molecule substitutions in each congener determines its ability to exert toxicity via AhR-mediated pathways. Co-planar congeners such as PCB126 have a much stronger affinity for the receptor than those that are planar such as PCB153. One of each type of congener was investigated to determine whether ATR-FTIR spectroscopy could elucidate a different mechanism of toxicity between the two. Figure 2A (see SI Table S4) shows that in mallard cells, PCB153 treatment was associated with alterations in lipids $\left(1709 \mathrm{~cm}^{-1}\right)$, amide I $\left(1624 \mathrm{~cm}^{-1}\right)$, and amide II $(1535 ; 1497$ $\left.\mathrm{cm}^{-1}\right)$, as well as in regions associated with collagen $\left(\mathrm{CH}_{3}\right.$ asymmetric bending, $1458 \mathrm{~cm}^{-1}$; symmetric $\mathrm{C}-\mathrm{O}$ stretching, $\left.1030 \mathrm{~cm}^{-1}\right)$ by using a PCA-LDA model with 10 PCs $(98 \%$ explained variance). The sensitivity values for this compound in Table 1 are considerably low (20-60\%), indicating not much difference between the control cells and those treated with three different levels of PCB153. Although solvent features might be present in collagen-related areas (nonane absorptions at $1500-1400 \mathrm{~cm}^{-1}$ due to $\mathrm{CH}_{3}$ bending), alterations of the spectra were not seen in mallard fibroblasts treated with PCB126. Previous study has shown that in fibroblast cells, PCB153 can cause an increase in cellular levels of type I collagen. $^{70}$ This may represent an AhR-independent pathway that PCB153 can mediate cellular effects through and that is detectable using ATR-FTIR spectroscopy. PCB126treated mallard cells (Figure 2B, see SI Table S5) showed alterations in lipids $\left(1744 ; 1705 \mathrm{~cm}^{-1}\right)$, amide I (1647; 1609 $\left.\mathrm{cm}^{-1}\right)$, amide II $\left(1504 \mathrm{~cm}^{-1}\right)$, and cytosine and guanine in DNA (C-N stretching, $1369 \mathrm{~cm}^{-1}$ ) through a PCA-LDA model using 10 PCs (95\% explained variance). In this model, sensitivities and specificities are relatively high for control cells ( sensitivity $=71 \%$; specificity $=89 \%)$ and cells treated with $10^{-8} \mathrm{M}$ PCB126 (sensitivity $=72 \%$; specificity $=85 \%$ ), indicating that these two groups are quite distinct from the others. The low sensitivities for $10^{-10} \mathrm{M}(56 \%)$ and $10^{-12} \mathrm{M}$ (48\%) PCB126 indicate that these groups are somewhere similar. Initially, the range of alterations induced appears quite similar, but there are crucial differences between the alterations induced by the two congeners (PCB153 and PCB126), such as collagen alterations in PCB153-treated fibroblasts, which when supported by evidence from other studies could reveal key toxicity mechanisms. In cells treated with PCB126, alterations in the DNA region of the spectra were more pronounced than in PCB153-treated cells. This may be mediated by binding to the $\mathrm{AhR}$ and downstream gene transcription processes as 


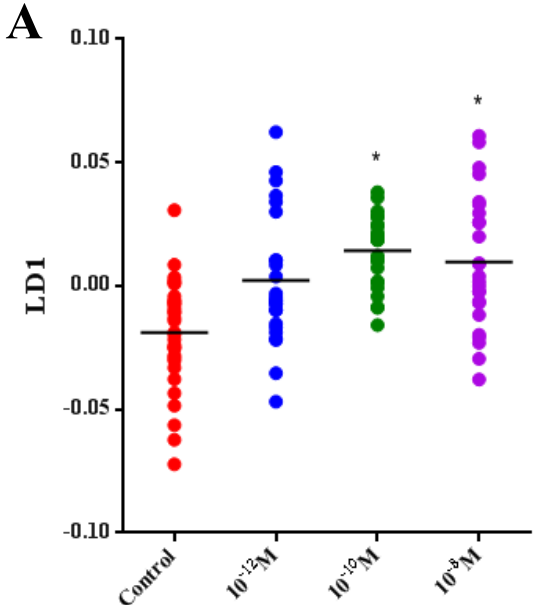

Concentration (M)

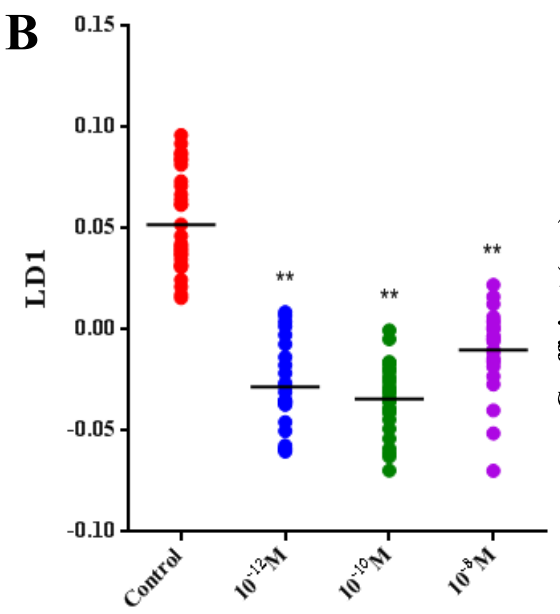

Concentration (M)
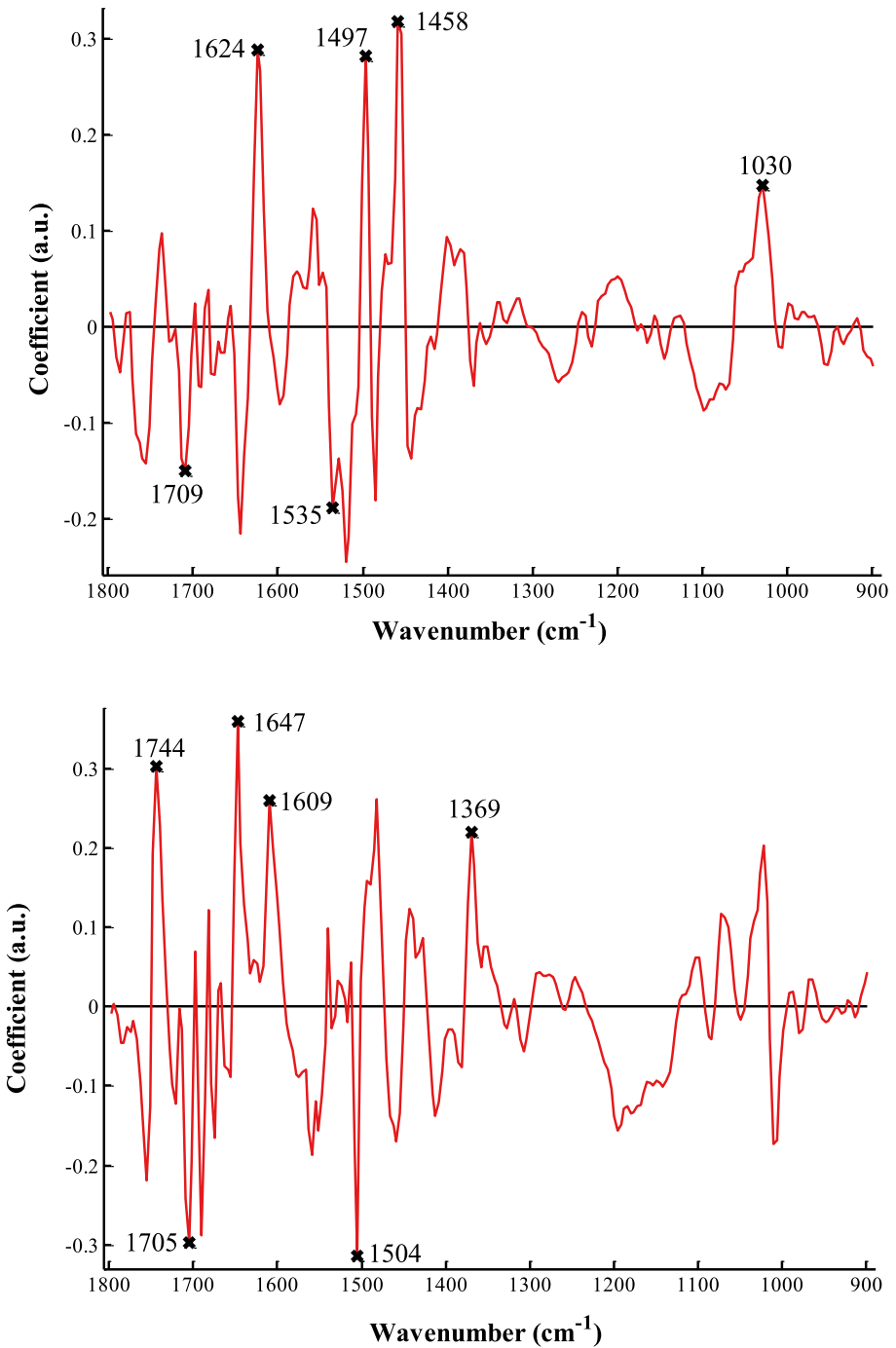

Figure 2. PCA-LDA score plots and corresponding LD1 loading plots with the top six wavenumbers highlighted from mallard cells treated with PCB126 and PCB153. Significance from control calculated using one-way ANOVA followed by Dunnett's post-hoc test $[P<0.05$ level $(*)$ or $P<$ 0.01 level (**)]. Mallard cells treated with (A) $10^{-8}, 10^{-10}$, and $10^{-12} \mathrm{M}$ PCB153 and (B) $10^{-8}, 10^{-10}$, and $10^{-12} \mathrm{M}$ PCB126.
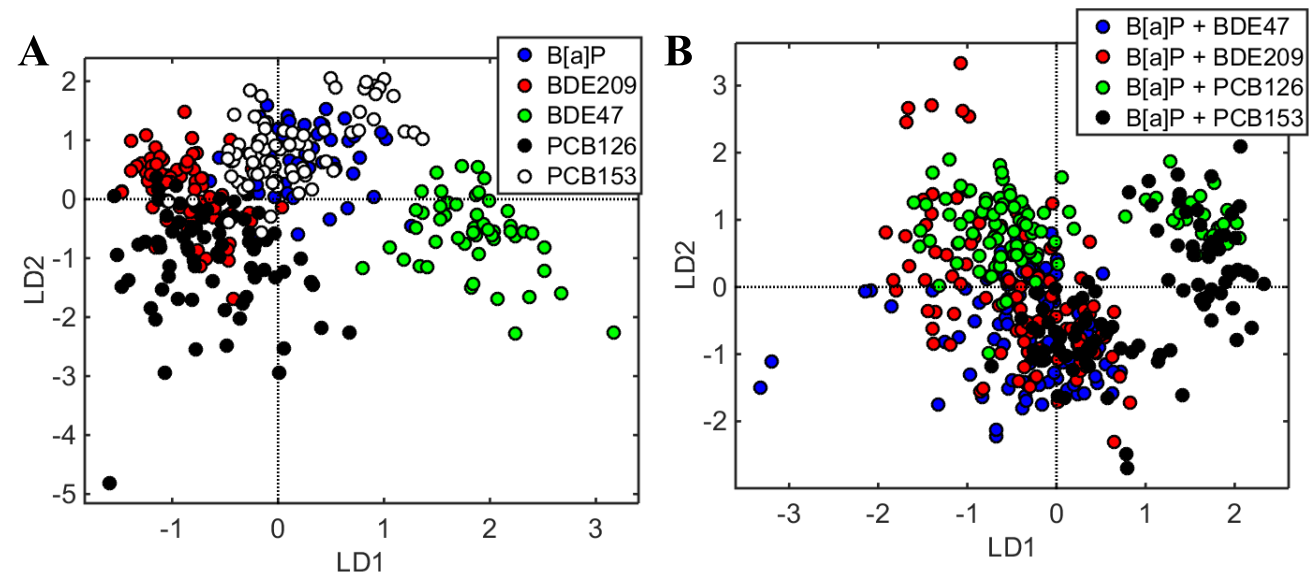

Figure 3. (A) PCA-LDA score plot for cells treated with single components (B[a]P, BDE209, BDE47, PCB126, and PCB153); (B) PCA-LDA score plot for cells treated with mixtures $(\mathrm{B}[a] \mathrm{P}+\mathrm{BDE} 47, \mathrm{~B}[a] \mathrm{P}+\mathrm{BDE} 209, \mathrm{~B}[a] \mathrm{P}+\mathrm{PCB} 126, \mathrm{~B}[a] \mathrm{P}+\mathrm{PCB} 153)$ in different concentration levels. $\mathrm{LD}$ stands for linear discriminant function based on the canonical variables scores of PCA-LDA.

PCB126 is a co-planar congener and therefore a more potent AhR agonist. PCB153 has a much weaker affinity for AhR binding and is hypothesized to exert toxicity via a number of other receptors. ${ }^{7}$ 
Identification of Interactions in Binary Mixtures. To investigate the interactions in real "observed" mixtures of $\mathrm{B}[a]$ $\mathrm{P}$ with BDEs and PCBs contaminants in terms of IR spectra, a PCA-LDA model was built comparing different mixtures (Figure 3). Figure 3A shows the PCA-LDA scores for cells exposed to the five different types of compounds $(\mathrm{B}[a] \mathrm{P}$, BDE209, BDE47, PCB126, and PCB153), where some clustering patterns are observed. Sensitivity and specificity values for this model are depicted in Table 2. For BDE209,

Table 2. Sensitivity and Specificity Based on PCA-LDA for Comparing Mallard Cells Exposed to Single Agents $(\mathrm{B}[a] \mathrm{P}$, BDE209, BDE47, PCB126, PCB153) and Mixtures (B $[a] P$ + BDE47, B $[a] \mathbf{P}+$ BDE209, B $[a] \mathbf{P}+$ PCB126, B $[a] \mathbf{P}+$ PCB153) Combining Different Concentration Levels $\left(10^{-6}-10^{-10} \mathrm{M} \mathrm{B}[a] \mathrm{P}, 10^{-8}-10^{-12} \mathrm{BDE} 209,10^{-8}-10^{-12}\right.$ BDE47, $10^{-8}-10^{-12}$ PCB126, $10^{-8}-10^{-12}$ PCB153)

\begin{tabular}{lcc} 
& sensitivity (\%) & specificity (\%) \\
single agent & & \\
$\mathrm{B}[a] \mathrm{P}$ & 42 & 95 \\
$\mathrm{BDE} 209$ & 89 & 90 \\
$\mathrm{BDE} 47$ & 98 & 99 \\
PCB126 & 77 & 95 \\
PCB153 & 68 & 90 \\
Mixture & & \\
$\mathrm{B}[a] \mathrm{P}+\mathrm{BDE} 47$ & 72 & 76 \\
$\mathrm{~B}[a] \mathrm{P}+\mathrm{BDE} 209$ & 37 & 90 \\
$\mathrm{~B}[a] \mathrm{P}+\mathrm{PCB} 126$ & 65 & 87 \\
$\mathrm{~B}[a] \mathrm{P}+\mathrm{PCB} 153$ & 56 & 90 \\
\hline
\end{tabular}

BDE47, and PCB126, the sensitivities are high $(89,98$, and $77 \%$, respectively), indicating that cells exposed to these compounds form very separated clusters, while for $\mathrm{B}[a] \mathrm{P}$ and PCB153, the sensitivities (42 and 68\%, respectively) indicate a mixing. Considering the binary mixtures (Figure $3 \mathrm{~B}$ ), only the mixture of $\mathrm{B}[a] \mathrm{P}$ with $\mathrm{BDE} 47$ seems to affect the cells differently (sensitivity $=72 \%)($ Table 2$)$. The other mixtures have superposed clustering (sensitivity $=37-56 \%$ ), indicating common cell modifications.

Spectral data from cells treated with individual chemical components were added together (once background alterations were removed) to produce an "expected" spectrum, which could be compared to the "observed" spectrum derived from cells treated with the actual binary mixture. The baselinesubtracted spectra from each single exposure were used since in theory baseline absorptions should be zero, although contribution of some cellular components can be obscured. This was performed to remove physical variations that can contribute to the baseline signal, especially sample thickness, optical path, and pressure on the ATR module. Therefore, using the baseline-subtracted spectra, the expected spectra should be ideally identical to the observed spectra.

To identify areas of the spectrum where the observed and expected spectra diverged, the plots were color-coded so that green areas represent where the observed spectrum is less than expected and red areas represent where the observed spectral result is greater than expected. Theoretically, when interactions occur in a mixture, the expected and observed spectrum will be significantly different and these areas need to be investigated as if the observed spectrum is greater than expected, enhanced toxicity may occur. ${ }^{72}$ Spectral differences related to shifting and appearance of new bands are associated to changes in the chemical structure of the samples associated with the presence or absence of the contaminants. As there were a number of predicted models tested, color-coding the spectra in this manner facilitates broad identification of interactions for consideration before more detailed analysis. This allows the researcher to rapidly answer experimental questions such as in which binary mixture is an interaction most likely to be occurring, where enhanced chemical action is most likely to be occurring, and which areas of the spectrum are most affected. Figures 4-7 show plots of expected and observed spectra for mallard cells treated with binary mixtures of $\mathrm{B}[a] \mathrm{P}$ with PBDEs or PCBs. The observed spectrum is derived from cells treated with the actual binary mixture (denoted by a solid line) and the expected spectra are based on an additive prediction using cells treated with individual chemical components (denoted by a dashed line).

The majority of the plots showed more green- or red-coded areas than white areas, which indicates that there is a match between the expected and observed spectra. This appears to suggest that interactions could be occurring when cells are treated with most of the binary mixtures; however, the extent of the difference between the expected and observed spectra is likely to be an important factor. There are irregularities in the red and green areas varying the contaminant and concentration due to the nature of the contaminant used and the effect of the concentration in possible chemical interactions, suggesting gain in the expected toxicity in spectra containing more red regions and reduction of the expected toxicity in spectra containing more green regions. Still, spectral results can be more complex to interpret as the range of alterations measured encompasses many toxicological endpoints. ${ }^{73}$ For toxicological assessment, cases where the observed is less than the expected are not as much of a concern as the prediction has been conservative. Overall, the spectra from cells treated with mixtures of $\mathrm{B}[\mathrm{a}] \mathrm{P}$ and BDE47 (Figure 4) had the most green areas, potentially signifying that these compounds may instigate less than additive alterations when in a mixture. There were also some regions indicating less than additive alterations in spectra from cells treated with $\mathrm{B}[a] \mathrm{P}$ and BDE209 (Figure 5), mostly when exposed to $10^{-10} \mathrm{M} \mathrm{B}[a] \mathrm{P}$ and $10^{-8} \mathrm{M}$ BDE209 (Figure 5C). However, some spectra were immediately notable as they had large red-coded areas. When assessing toxicity, these areas would warrant further investigation as they could represent possible biomolecular endpoints, where greater than additive mixture effects may be occurring. Failure to predict and capture enhanced mixture toxicity could put the species under consideration at risk. Mallard cells exposed to mixtures of $\mathrm{B}[a]$ $\mathrm{P}$ and BDE209 (Figure 5) had large spectral areas, where greater than expected alterations were occurring. In particular, the plot of cells treated with $10^{-6} \mathrm{M} \mathrm{B}[a] \mathrm{P}$ and $10^{-8} \mathrm{M}$ BDE209 (Figure 5A) was more than $90 \%$ red and the observed alterations were more than double those expected in some areas. A similar effect was also seen in cells exposed to $10^{-6} \mathrm{M}$ $\mathrm{B}[a] \mathrm{P}$ and $10^{-8} \mathrm{M} \mathrm{PCB} 153$ (Figure 6A).

Depending on the binary mixture and concentration, the biomolecules that were most affected varied, which can occur as IR methods measure all biomolecules in a cell and thus all toxicological endpoints. This makes the technique more suited to broad assessment of trends between expected and observed spectra. For example, in the ca. $900-1100 \mathrm{~cm}^{-1}$ region, mixtures were most likely to generate less than additive alterations or mixture effects where the expected and observed spectra match well. Used in this manner, ATR-FTIR 

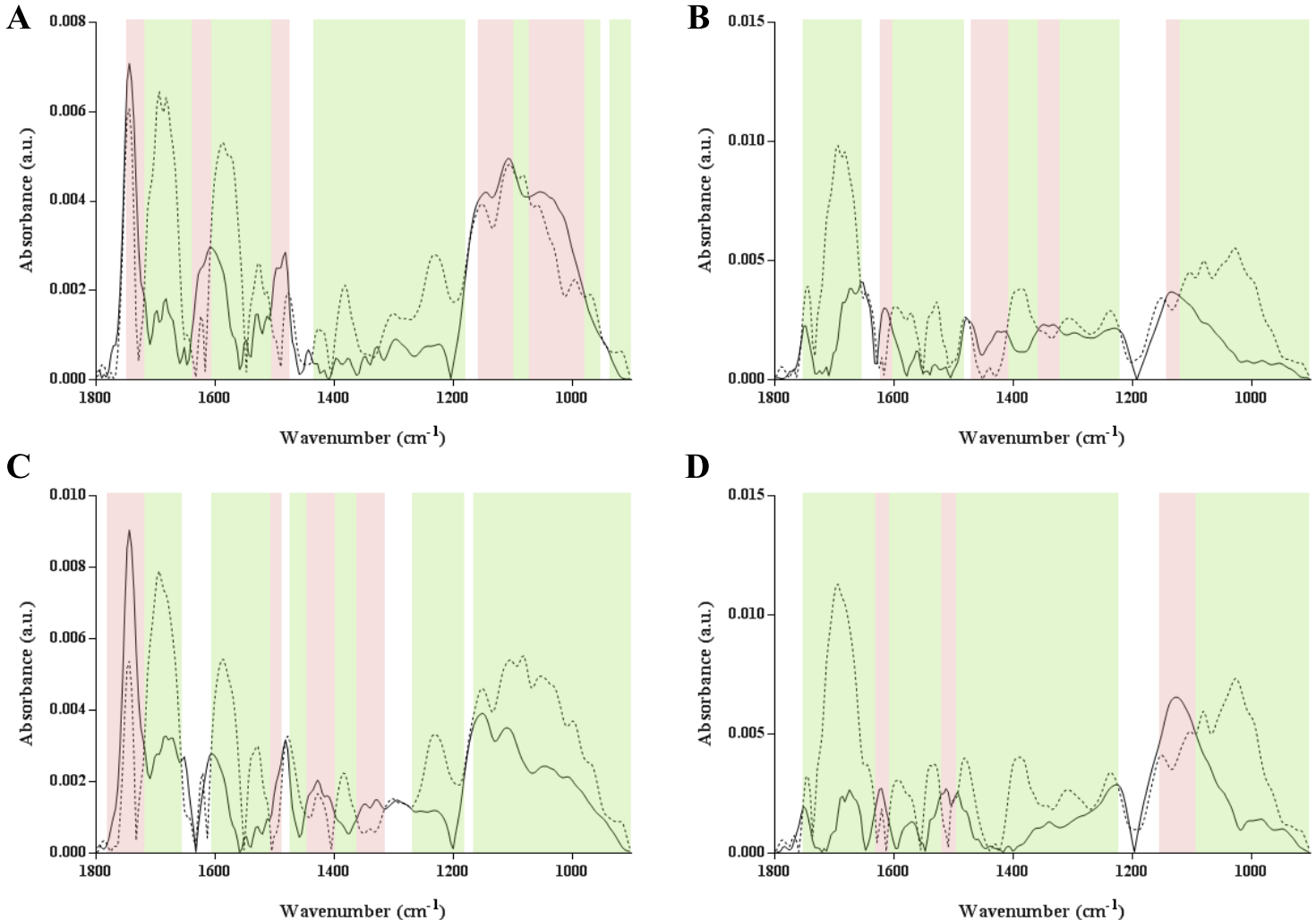

Figure 4. Additive spectral models, showing preprocessed (first-order differentiation baseline-corrected and vector-normalized) expected and observed spectra from mallard cells treated with a binary mixture of $\mathrm{B}[a] \mathrm{P}$ and BDE47. Expected spectra are denoted by the dashed line, and observed spectra are denoted by the solid line. The green areas represent where the observed spectrum is less than the expected spectrum, and red areas represent where the observed spectral result is greater than the expected spectrum. (A) $\mathrm{B}[a] \mathrm{P} 10^{-6} \mathrm{M}$ and $\mathrm{BDE} 4710^{-8} \mathrm{M}$; $(\mathrm{B}) \mathrm{B}[a] \mathrm{P} 10^{-6} \mathrm{M}$ and BDE47 $10^{-12} \mathrm{M}$; (C) B[a]P $10^{-10} \mathrm{M}$ and BDE47 $10^{-8} \mathrm{M}$; and (D) B[a]P $10^{-10} \mathrm{M}$ and BDE47 $10^{-12} \mathrm{M}$.

spectroscopy can provide a simple and fast tool to identify general areas of divergence between expected and observed spectra, making it an ideal screening tool for mixture interactions. It may be used to identify mixture effect trends and direct further in-depth analysis.

Predicting Effects of Binary Mixture Using IR Spectroscopy. An essential part of the study of mixtures is investigating if the effects of a chemical combination can be accurately predicted so that detrimental mixture toxicity can be circumvented. As the majority of mixtures exhibit additive toxicity, regulatory assessments are commonly based on this assumption, so in this study, a predictive pseudospectrum was created based on the model of additivity. The expected and observed spectra were compared to understand how accurate the predictive model was as well as looking at how and why the two spectral results might differ. The use of a predictive peudospectra created from individual spectral data may be useful in reducing the scope of mixture toxicity investigations as it may not be practical to actually test all possible mixtures.

It was immediately visually evident that the majority of observed spectral alterations induced by binary mixtures of $\mathrm{B}[\mathrm{a}] \mathrm{P}$ and $\mathrm{PBDE}$ or $\mathrm{PCB}$ congeners did not match those expected using component chemical data. This was also confirmed by a goodness-of-fit analysis using a similarity coefficient (Table 3 ). This coefficient shows that majority of expected and observed spectra are lesser than 50\% similar $(\gamma<$ $0.5)$. The mixture less similar between expected and observed spectra is for $\mathrm{B}[a] \mathrm{P} 10^{-10} \mathrm{M}$ plus PCB126 $10^{-8} \mathrm{M}(\gamma=0.03)$. Comparing the spectra for this mixture (Figure $7 \mathrm{C}$ ), it is possible to identify most green regions, indicating a decrease of toxicity of the real spectrum in comparison to the theoretical one. Only three mixtures had similarity above $50 \%(\gamma>0.5)$, implying that those mixtures induce spectral alterations, which are closer to an additive mixture model. The highest similarity between the expected and observed spectra is for $\mathrm{B}[\mathrm{a}] \mathrm{P} 10^{-6}$ $\mathrm{M}$ plus BDE209 $10^{-8} \mathrm{M}(\gamma=0.84)$, in which the spectrum for this mixture (Figure 5A) indicates a prevalence of red regions, thus a gain of toxicity.

In many spectral areas, the observed alterations were greater than expected, as seen in mallard cells treated with binary mixtures of $\mathrm{B}[a] \mathrm{P}$ and BDE209 (Figure 5), where observed absorbances were actually much greater than the expected absorbances in many spectral regions. Dissimilar to cells treated with $\mathrm{BDE} 47$ containing binary mixtures, spectra from fibroblasts treated with binary mixtures of $\mathrm{B}[a] \mathrm{P}$ and BDE47 (Figure 4) revealed that across most regions of the spectrum, the observed absorbances were smaller than expected. BDE209 and BDE47 have been reported as having many common toxicities, but the main difference between the two types of PBDE-containing mixtures is that BDE209 is much larger and more brominated than the other congener. ${ }^{74}$ This physical difference could alter how the molecule interacts with targets and other chemicals and may explain differences in adherence to the additive model that can be seen between the two mixture types. Observed spectra from avian cells treated with binary mixtures, containing the highest concentration of either PBDE congener with $\mathrm{B}[a] \mathrm{P}$ (Figures $4 \mathrm{~A}, \mathrm{C}$ and $5 \mathrm{~A}, \mathrm{C}$ ), both showed consistent enhancement of a peak at $1750 \mathrm{~cm}^{-1}$ above 

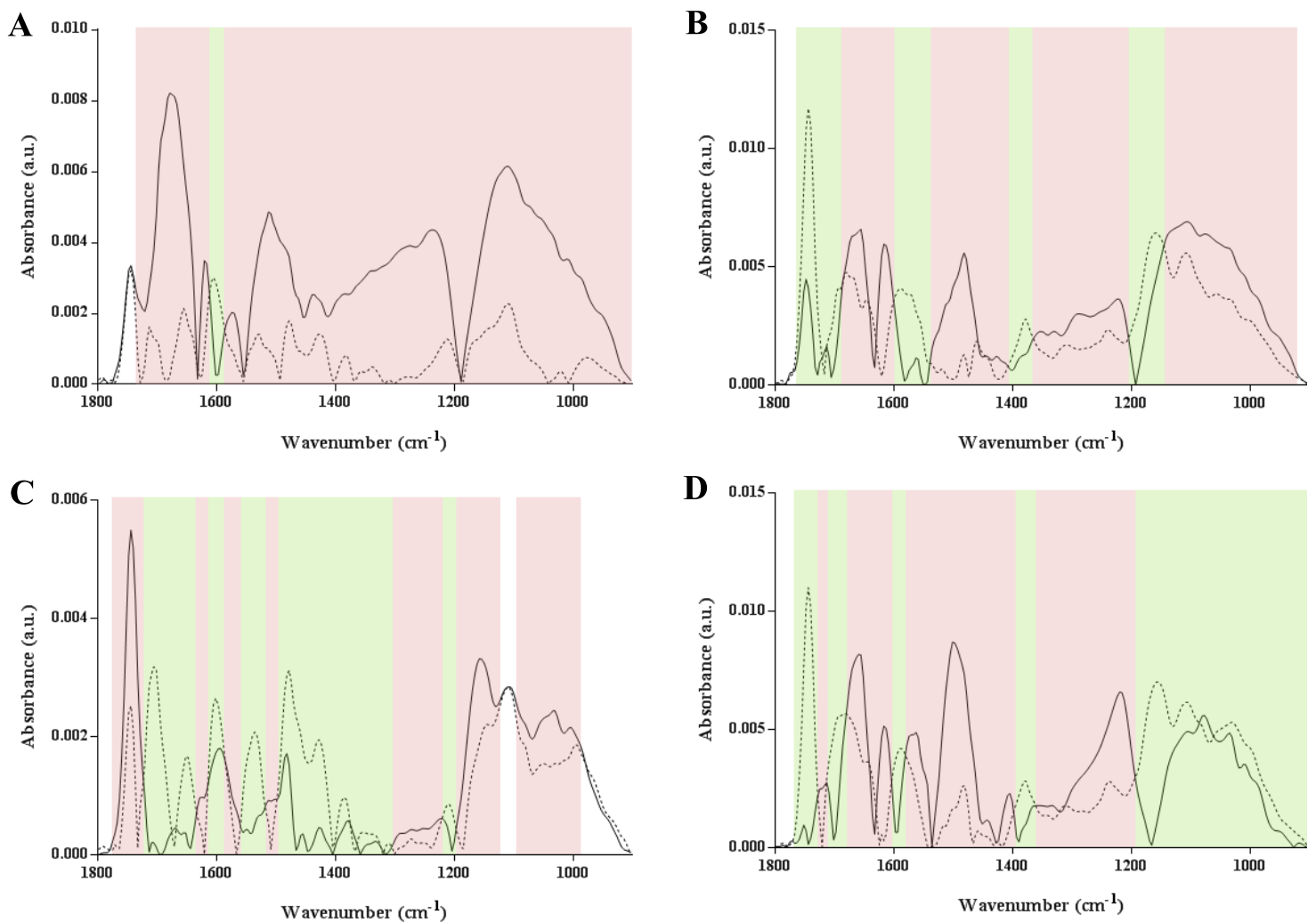

Figure 5. Additive spectral models, showing preprocessed (first-order differentiation baseline-corrected and vector-normalized) expected and observed spectra from Mallard cells treated with a binary mixture of $\mathrm{B}[a] \mathrm{P}$ and BDE209. Expected spectra are denoted by the dashed line, and observed spectra are denoted by the solid line. The green areas represent where the observed spectrum is less than the expected spectrum, and the red areas represent where the observed spectral result is greater than the expected spectrum. (A) $\mathrm{B}[a] \mathrm{P} 10^{-6} \mathrm{M}$ and $\mathrm{BDE} 20910^{-8} \mathrm{M}$; $(\mathrm{B}) \mathrm{B}[a] \mathrm{P}$ $10^{-6} \mathrm{M}$ and BDE209 $10^{-12} \mathrm{M}$; (C) B[a]P $10^{-10} \mathrm{M}$ and BDE209 $10^{-8} \mathrm{M}$; and (D) B [a]P $10^{-10} \mathrm{M}$ and BDE209 $10^{-12} \mathrm{M}$.

that expected. This is the major region associated with $\mathrm{C}=\mathrm{O}$ vibrations of lipids and may denote greater-than-additive lipid damage, which occurs when mallard cells are co-exposed to concentrations of $10^{-8} \mathrm{M}$ PBDE congeners with $\mathrm{B}[a] \mathrm{P}$.

The observed spectral alterations in mallard fibroblasts treated with $\mathrm{B}[a] \mathrm{P}$ and $\mathrm{PCB} 153$ (Figure 6) were typically greater than those expected over most regions of the spectrum. This could be seen at all concentrations except $\mathrm{B}[a] \mathrm{P} 10^{-10} \mathrm{M}$ and PCB153 $10^{-8} \mathrm{M}$ (Figure $6 \mathrm{C}$ ) when there were also quite a number of spectral areas where the observed absorbances were smaller than expected. In those combinations that showed largely greater-than-additive observed alterations, the peaks in the ca. $1650-1750 \mathrm{~cm}^{-1}$ area were also notably enhanced. This was also observed in cells treated with binary mixtures of $\mathrm{B}[a]$ $\mathrm{P}$ with $\mathrm{PBDE}$ congeners. When treated with $\mathrm{B}[a] \mathrm{P}$ and PCB126 (Figure 7), avian cells showed reduced observed alterations compared to binary mixtures, which included PCB153. In these mixtures, the differences between the observed and expected spectra were also smaller than those seen in cells treated with PCB153, possibly implying that the mixtures containing $\mathrm{B}[a] \mathrm{P}$ and $\mathrm{PCB} 126$ exhibit a closer approximation of additive toxicity. The general decrease in observed spectral alterations may be due to the enhanced AhRbinding affinity of co-planar PCB126 in comparison to the planar PCB153 congener. ${ }^{75}$ There may be binding competition of receptors between $\mathrm{B}[a] \mathrm{P}$ and $\mathrm{PCB} 126$, which led to a reduction in mixture toxicity. Further exploration by Western blot analysis of CYP1A1, which is downstream of the receptor (see SI Table S7), did show less expression of CYP1A1 in mallard cells treated with binary mixtures containing PCB126 compared to those containing PCB153, but the result was not found to be significant. This may indicate that the overall mixture toxicity is occurring via AhR-independent mechanisms or that incorporation of all toxic endpoints across the spectrum may mask specific toxicities, which need further testing for elucidation.

A number of chemical combinations were tested and the results have varied across the spectrum with less-than-additive or more-than-additive alterations being observed compared to the result expected using predictive additive models. Only a very small proportion of the spectrum for each combination showed a good fit between the observed and expected results. This may be caused by interactions in the mixtures, indicating that an additive model is not appropriate or may be due to the scale of toxic endpoints incorporated into an IR spectrum. The AhR pathway, and induction of downstream expression of phase I and II metabolism enzymes, is known to be a common pathway involved in metabolism of the contaminants studied, some of which are reported to have AhR-binding affinities. Although less-than-expected results are not concerning from a regulatory perspective as they represent less toxicity than expected, these results also occurred in a large proportion of spectral areas. Activation of the AhR pathway and metabolism of $\mathrm{B}[a] \mathrm{P}$ is essential for its toxicity; it may be that the presence of other PCB or PBDE contaminants shifts the pathway toward detoxification so that more $\mathrm{B}[a] \mathrm{P}$ is fully detoxified than converted to the pro-carcinogen form. This has been observed in cells exposed to mixtures of $\mathrm{B}[a] \mathrm{P}$ as well as other 

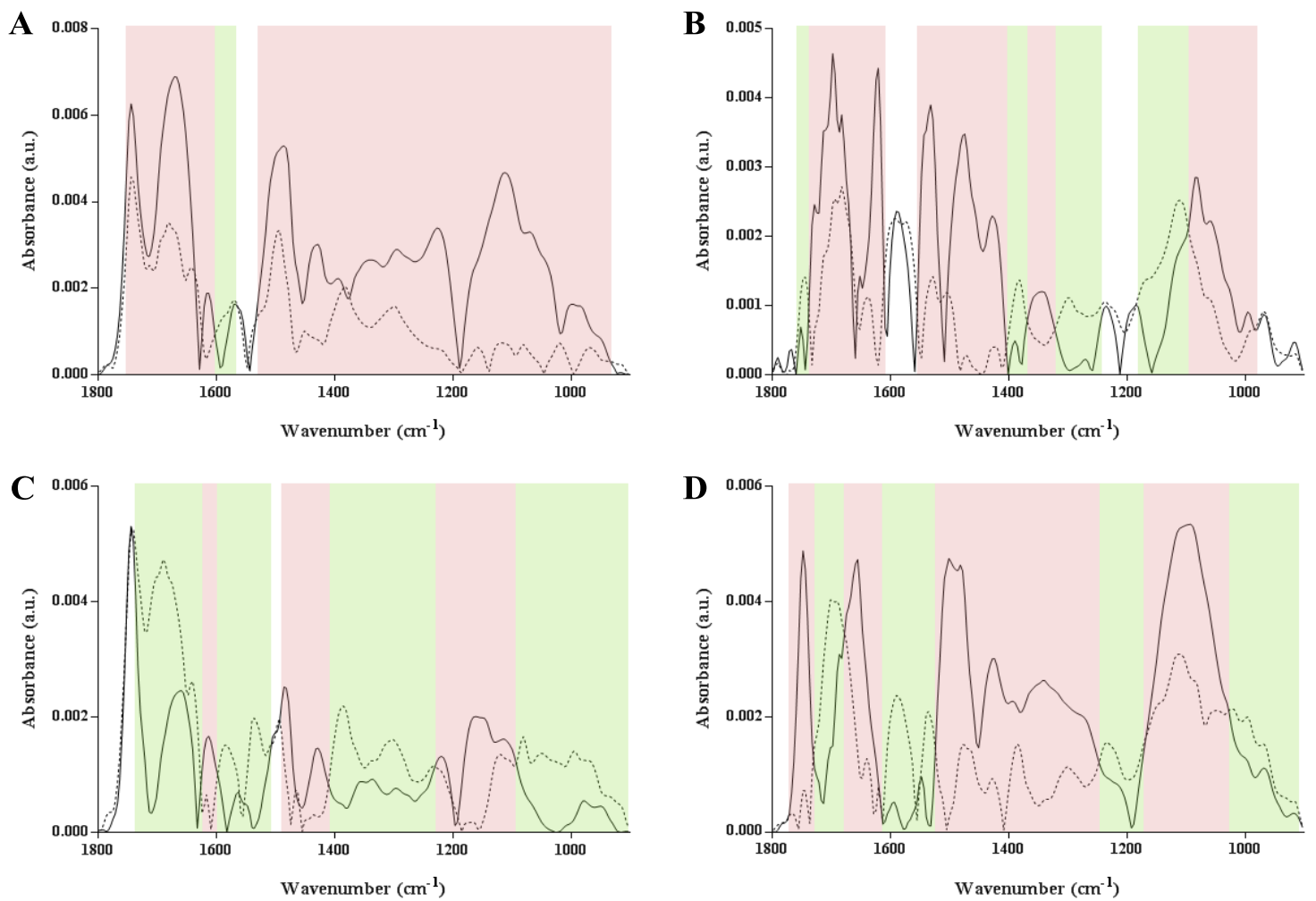

Figure 6. Additive spectral models, showing preprocessed (first-order differentiation baseline-corrected and vector-normalized) expected and observed spectra from mallard cells treated with a binary mixture of $\mathrm{B}[a] \mathrm{P}$ and PCB153. Expected spectra are denoted by the dashed line, and observed spectra are denoted by the solid line. The green areas represent where the observed spectrum is less than the expected spectrum, and the red areas represent where the observed spectral result is greater than the expected spectrum. (A) $\mathrm{B}[a] \mathrm{P} 10^{-6} \mathrm{M}$ and $\mathrm{PCB} 15310^{-8} \mathrm{M}$; $(\mathrm{B}) \mathrm{B}[a] \mathrm{P}$ $10^{-6} \mathrm{M}$ and PCB153 $10^{-12} \mathrm{M}$; (C) B $[a] \mathrm{P} 10^{-10} \mathrm{M}$ and PCB153 $10^{-8} \mathrm{M}$; and (D) B [a]P $10^{-10} \mathrm{M}$ and PCB153 $10^{-12} \mathrm{M}$.

Table 3. Similarity Coefficient $(\gamma)$ Used as Goodness-of-Fit Indicator between Expected and Observed Binary Mixture Spectra for Mallard Cells

\begin{tabular}{|c|c|}
\hline mixture & similarity coefficient $(\gamma)$ \\
\hline $\mathrm{B}[a] \mathrm{P} 10^{-10} \mathrm{M}+\mathrm{BDE} 20910^{-8} \mathrm{M}$ & 0.49 \\
\hline $\mathrm{B}[\mathrm{a}] \mathrm{P} 10^{-10} \mathrm{M}+\mathrm{BDE} 20910^{-12} \mathrm{M}$ & 0.32 \\
\hline $\mathrm{B}[a] \mathrm{P} 10^{-10} \mathrm{M}+\mathrm{BDE} 4710^{-8} \mathrm{M}$ & 0.36 \\
\hline $\mathrm{B}[a] \mathrm{P} 10^{-10} \mathrm{M}+\mathrm{BDE} 4710^{-12} \mathrm{M}$ & 0.24 \\
\hline $\mathrm{B}[a] \mathrm{P} 10^{-10} \mathrm{M}+\mathrm{PCB} 12610^{-8} \mathrm{M}$ & 0.03 \\
\hline $\mathrm{B}[\mathrm{a}] \mathrm{P} 10^{-10} \mathrm{M}+\mathrm{PCB} 12610^{-12} \mathrm{M}$ & 0.47 \\
\hline $\mathrm{B}[a] \mathrm{P} 10^{-10} \mathrm{M}+\mathrm{PCB} 15310^{-8} \mathrm{M}$ & 0.31 \\
\hline $\mathrm{B}[\mathrm{a}] \mathrm{P} 10^{-10} \mathrm{M}+\mathrm{PCB} 15310^{-12} \mathrm{M}$ & 0.63 \\
\hline $\mathrm{B}[\mathrm{a}] \mathrm{P} 10^{-6} \mathrm{M}+\mathrm{BDE} 20910^{-8} \mathrm{M}$ & 0.84 \\
\hline $\mathrm{B}[a] \mathrm{P} 10^{-6} \mathrm{M}+\mathrm{BDE} 20910^{-12} \mathrm{M}$ & 0.59 \\
\hline $\mathrm{B}[a] \mathrm{P} 10^{-6} \mathrm{M}+\mathrm{BDE} 4710^{-8} \mathrm{M}$ & 0.46 \\
\hline $\mathrm{B}[\mathrm{a}] \mathrm{P} 10^{-6} \mathrm{M}+\mathrm{BDE} 4710^{-12} \mathrm{M}$ & 0.19 \\
\hline $\mathrm{B}[\mathrm{a}] \mathrm{P} 10^{-6} \mathrm{M}+\mathrm{PCB} 12610^{-8} \mathrm{M}$ & 0.30 \\
\hline $\mathrm{B}[a] \mathrm{P} 10^{-6} \mathrm{M}+\mathrm{PCB} 12610^{-12} \mathrm{M}$ & 0.04 \\
\hline $\mathrm{B}[a] \mathrm{P} 10^{-6} \mathrm{M}+\mathrm{PCB} 15310^{-8} \mathrm{M}$ & 0.43 \\
\hline $\mathrm{B}[\mathrm{a}] \mathrm{P} 10^{-6} \mathrm{M}+\mathrm{PCB} 15310^{-12} \mathrm{M}$ & 0.12 \\
\hline
\end{tabular}

PAHs. ${ }^{76,77}$ If IR spectroscopy was used as a predictive tool as described here, the mixtures that display greater than expected alterations according to an additive model would be those that represent the most risk to environmental organisms. The combinations that lead to the most greater-than-expected effects are seen in mallard cells treated with binary mixtures, including $\mathrm{B}[a] \mathrm{P}$ with $\mathrm{BDE} 209$ (Figure 5) or PCB153 (Figure $6)$, and deviations in the region around ca. $1650-1750 \mathrm{~cm}^{-1}$ are notable. As a greater-than-additive effect in this area of the spectrum was induced by many of the combinations tested, it may represent a common mechanism for environmental binary mixtures of $\mathrm{B}[a] \mathrm{P}$ with $\mathrm{PBDE}$ or $\mathrm{PCBs}$, which can lead to enhancement of toxicity.

Evidence of potential greater than expected alterations to some biomolecules represents a cause for further investigation, particularly as these effects were observed in mallard fibroblast cells, a species commonly found in the environment. The results also suggest that the effects of binary mixtures composed of $\mathrm{B}[a] \mathrm{P}$ with $\mathrm{PCBs}$ or $\mathrm{PBDEs}$ are contaminant and dose-dependent, where a combination effect was observed involving a possible mechanism of $\mathrm{B}[a] \mathrm{P}$ with $\mathrm{PCBs}$ or PBDEs, enhancing the toxicity in mixtures. Nevertheless, as limitation, the use of fixed cells in this paper may obscure subtler chemical shifts that can provide relevant biochemical information due to cross-linkage. In addition, the mechanism and toxicity results are dependent on cell type; for this reason, multiple cell types are needed for a more robust study. However, this paper lends evidence for the rationale that all possible mixtures need to be considered during regulatory decisions as interactions between components or at biological target sites can lead to deviations from the additive model. Specific toxicology testing of mixtures on this scale would be daunting, but we have shown that a panel of binary mixtures, composed of various chemicals at different concentrations, can be studied in a high-throughput manner using ATR-FTIR spectroscopy. Further testing is needed to understand why so much of the observed spectral alterations deviate away from the predictive additive model, but IR spectroscopy is a unique approach that can study the 

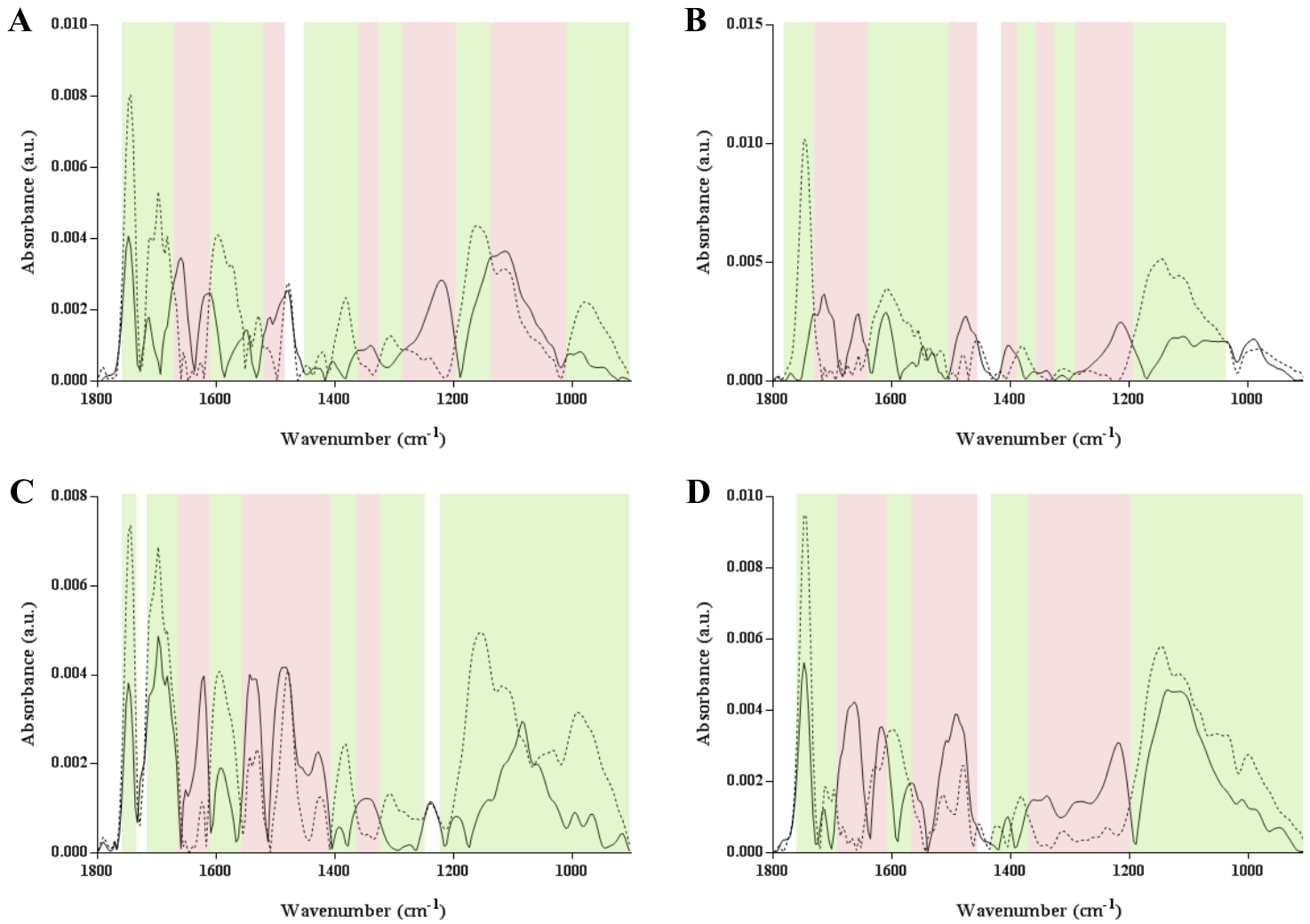

Figure 7. Additive spectral models showing preprocessed (first-order differentiation baseline-corrected and vector-normalized) expected vs. observed spectra from mallard cells treated with a binary mixture of $\mathrm{B}[\mathrm{a}] \mathrm{P}$ and $\mathrm{PCB} 126$. Expected spectra are denoted by the dashed line, and observed spectra are denoted by the solid line. The green areas represent where the observed spectrum is less than the expected spectrum, and the red areas represent where the observed spectral result is greater than the expected spectrum. (A) $\mathrm{B}[\mathrm{a}] \mathrm{P} 10^{-6} \mathrm{M}$ and $\mathrm{PCB} 12610^{-8} \mathrm{M}$; $(\mathrm{B}) \mathrm{B}[a] \mathrm{P}$ $10^{-6} \mathrm{M}$ and PCB126 $10^{-12} \mathrm{M}$; (C) B $[a] \mathrm{P} 10^{-10} \mathrm{M}$ and PCB126 $10^{-8} \mathrm{M}$; and (D) B $[a] \mathrm{P} 10^{-10} \mathrm{M}$ and PCB126 $10^{-12} \mathrm{M}$.

effects of binary mixtures at the biomolecular level. It may have application as a tool to screen chemical mixture-induced alterations for nonconformance to additivity and to direct further toxicology testing. This would be particularly effective when paired with color-coding of the spectra to indicate where deviation from the additive model and possible interaction occurs. However, although IR spectroscopy can act as a complementary tool to investigate the effect of contaminants in cells, it cannot be used as a single instrumental technique. Other techniques should be employed to help solve the complexity of the system under investigation, providing additional information that can enrich the IR data.

\section{MATERIALS AND METHODS}

Test Agents. Stocks of PBDE congeners 47 and 209 were purchased and dissolved in nonane at a concentration of 50 $\mu \mathrm{g} / \mathrm{mL}$, from LGC Standards (Teddington, UK). PCBs 153 and 126 were purchased as powders from Greyhound Chromatography and Allied Chemicals (Birkenhead, UK) and made up in nonane (anhydrous $\geq 99 \%$, Sigma-Aldrich, Dorset, UK). B $[a] \mathrm{P}$ was purchased in powder form Sigma and dissolved in dimethyl sulfoxide (DMSO) ( $\geq 99 \%$, SigmaAldrich, Dorset, UK). Stock solutions of treatment chemicals were made up to a concentration of $2 \mu \mathrm{M}$ in DMSO and then serially diluted in DMSO to the required experimental concentrations. Vehicle controls consisted of the same amount of DMSO as used in chemical treatments, spiked with equal quantities of nonane.
Cell Culture. Mallard (Anas platyrhynchos) dermal fibroblasts were grown in Dulbecco's modified Eagle's medium (DMEM) supplemented with $10 \%$ heat-inactivated fetal bovine serum (FBS), 2\% chicken serum (Sigma-Aldrich), 1\% nonessential amino acids (Thermo Fisher Scientific, Nottinghamshire, UK), and a penicillin and streptomycin mixture (100 $\mathrm{U} / \mathrm{mL}$ and $100 \mu \mathrm{g} / \mathrm{mL}$, respectively). Cells were cultured in a humidified atmosphere with $5 \% \mathrm{CO}_{2}$ in air at a temperature of $37^{\circ} \mathrm{C}$. Subculture was performed twice weekly by disaggregation with trypsin $(0.05 \%) /$ EDTA $(0.02 \%)$ solution before spinning at $1000 \times \mathrm{g}$ for $5 \mathrm{~min}$. The resultant cell pellet was then resuspended in fresh complete DMEM and seeded into T75 flasks for routine subculture or T25 for cell experiments and Western blotting [method provided in SI]. Unless stated otherwise, all cell culture consumables were purchased from Lonza (Verviers, Belgium).

Cell Experiments. After seeding into T25 flasks, cultures were left for $24 \mathrm{~h}$ to allow cells to attach and enter into Sphase. After $24 \mathrm{~h}$, the cells were treated with either single agents of $\mathrm{B}[a] \mathrm{P}, \mathrm{BDE} 47, \mathrm{BDE} 209, \mathrm{PCB} 126$, or $\mathrm{PCB} 153$ or binary mixtures of $10^{-6}$ or $10^{-10} \mathrm{M} \mathrm{B}[a] \mathrm{P}$ with a $\mathrm{PCB}$ or PBDE congener at $10^{-8}$ or $10^{-12} \mathrm{M}$. Experiments for single substances and binary mixtures were conducted in parallel. These concentrations were arbitrarily selected aiming to simulate low concentrations in the cellular system found in real environmental conditions. ${ }^{62,78-82}$ For single agent treatments, $25 \mu \mathrm{L}$ of the appropriate treatment was added to each flask as well as $25 \mu \mathrm{L}$ of DMSO so the effects could be compared to binary mixture exposures, which involved treating 
with $25 \mu \mathrm{L}$ each of two chemicals. Vehicle controls were treated with $50 \mu \mathrm{L}$ of DMSO (with nonane). Total DMSO concentrations did not exceed $1 \% \mathrm{v} / \mathrm{v}$. The cells were exposed to treatments for $24 \mathrm{~h}$ before they were disaggregated with trypsin, washed three times with $70 \%$ ethanol to remove residual media, and then fixed for $24 \mathrm{~h}$ in $70 \%$ ethanol. After fixation, the cells were pipetted onto IR-reflective low-E glass slides (Kevley Technologies, Chesterland, $\mathrm{OH}$ ) and allowed to dry in air before being placed in a desiccator for $24 \mathrm{~h}$ to remove any remaining water. This procedure was repeated at five different points in time to give five technical replicates $(n=$ 5,5 spectra each) recorded in sequence, in a time frame of approximately $12.5 \mathrm{~min}$ ( $2.5 \mathrm{~min}$ per technical replicate). As a result, 25 spectra were recorded for each concentration level.

ATR-FTIR Spectroscopy. Five spectra per slide were acquired using a Bruker TENSOR 27 FTIR spectrometer with Helios ATR attachment, which contained a diamond IRE with a sampling area of $250 \mu \mathrm{m} \times 250 \mu \mathrm{m}$ (Bruker Optics, Coventry, UK). The spectra were acquired with an $8 \mathrm{~cm}^{-1}$ spectral resolution with 32 co-additions, giving rise to a 3.84 $\mathrm{cm}^{-1}$ spectral data spacing. A mirror velocity of $2.2 \mathrm{kHz}$ was used. Before each sample, a background measurement was taken to account for atmospheric changes and the diamond was cleaned with distilled water between samples.

Expected IR Spectra. Expected IR spectra for binary mixtures were constructed based on an additive model following Beer-Lambert's law, in which the total observed absorbance in each wavenumber $k\left(A_{k, \text { total }}\right)$ is the result of the sum of the absorbance for all chemical components in this same wavenumber $\left(A_{k, 1}, A_{k, 2}, \ldots, A_{k, n}\right)^{83}$

$$
A_{k, \text { total }}=A_{k, 1}+A_{k, 2}+\cdots+A_{k, n}
$$

For a binary mixture of components $A$ and $B$ ( $j$ wavenumbers)

$$
\begin{aligned}
& s=b \varepsilon \\
& A_{A B j}=A_{A j}+A_{B j}=c_{A} s_{A j}+c_{B} s_{B j} \\
& {\left[A_{A B 1}, A_{A B 2}, \ldots, A_{A B j}\right]=\left[c_{A}, c_{B}\right]\left[\begin{array}{llll}
s_{A 1} & s_{A 2} & \ldots & s_{A j} \\
s_{B 1} & s_{B 2} & \ldots & s_{B j}
\end{array}\right]} \\
& \mathrm{a}=\mathrm{c} \times \mathrm{s}
\end{aligned}
$$

where $s$ is the product of the optical path length $(b)$ by the molar absorptivity coefficient $(\varepsilon)$; $c$ is the concentration for individual components; $\mathbf{a}$ is the resulting binary mixture spectrum; $\mathbf{s}$ is the spectrum for individual components; and $\mathbf{c}$ is the relative concentration between the components.

Thus, the expected mixture spectra were built adding the IR spectra from cell exposed to single contaminants, where the weight for each spectrum is the relative contaminant concentration. The same experimental concentrations in the real binary mixtures were used to generate the expected binary mixture spectra.

Spectral Processing and Computational Analysis. Computational analysis was performed within MATLAB 2013a (The MathsWorks, MA) environment using an inhouse developed toolbox called IRootLab (http://trevisanj.github.io/irootlab/) and the Classification Toolbox for MAT$\mathrm{LAB} .{ }^{84}$ Raw spectra were cut to the fingerprint region (900$\left.1800 \mathrm{~cm}^{-1}\right)$. Spectra were first-order differentiation baselinecorrected, vector-normalized, and mean-centered. Principal component analysis (PCA) was combined with linear discriminant analysis (LDA) to allow exploratory analysis of treatment-induced spectral alterations. PCA reduces the original spectral data set into a few number of principal components (PCs) accounting for the majority of the explained variance while reducing noise. Each PC is composed of scores and loadings, representing the variance on sample and variable (i.e., wavenumber) directions, respectively. ${ }^{85}$ PCA also solves problems of ill-conditioned data (data with large condition number) by reducing redundant information across the spectra and solving collinearity problems. The PCA scores are then used as input variables for LDA. ${ }^{86} \mathrm{LDA}$ is a supervised classification technique that is used to obtain interclass separation through a Mahalanobis distance calculation. The PCA-LDA classification scores $\left(c f\left(\mathbf{t}_{i}\right)\right)$ are calculated in a nonBayesian form as follows ${ }^{86,87}$

PCA decomposition

$$
\mathbf{X}=\mathbf{T} \mathbf{P}^{\mathrm{T}}+\mathbf{E}
$$

LDA

$$
c f\left(\mathbf{t}_{i}\right)=\left(\mathbf{t}_{i}-\overline{\mathbf{t}}_{k}\right)^{\mathrm{T}} C_{\text {pooled }}^{-1}\left(\mathbf{t}_{i}-\overline{\mathbf{t}}_{k}\right)
$$

where $\mathbf{X}$ represents the spectral data set; $\mathbf{T}$ is the PCA scores; $\mathbf{P}$ is the PCA loadings; $\mathbf{E}$ is the PCA residuals; $\mathbf{t}_{i}$ is the scores vector for a given sample $i$; $\overline{\mathbf{t}}_{k}$ is the mean scores vector for class $k$; $\mathbf{C}_{\text {pooled }}$ is the pooled covariance matrix; and $\mathrm{T}$ denotes the matrix transpose operation.

PCA-LDA is one of the most used classification techniques for spectral data due to its relative simplicity, ${ }^{86,88}$ being a powerful technique for analyzing classes with similar variance structures and data sets with small number of samples. ${ }^{86,87,89}$ Cross-validated PCA-LDA (leave-one-out cross-validation) was performed. Significance was determined in GraphPad Prism 4 (GraphPad Software Inc., CA) using one-way ANOVA followed by Dunnett's post-hoc test. Significance testing was performed using sample means rather than all spectral data. Goodness-of-fit between the model and observed result was estimated by a similarity coefficient $(\gamma)$ calculated in a classical least-squares sense as follows

$$
\gamma=\mathbf{x} \hat{\mathbf{s}}^{\mathrm{T}}\left(\hat{\mathbf{s}} \hat{\mathbf{s}}^{\mathrm{T}}\right)^{-1}
$$

where $\mathbf{x}$ is the "observed" spectra and $\hat{\mathbf{s}}$ is the "expected" spectra.

As a result, $\gamma$ is a real number indicating the degree of similarity between the observed and expected spectra. Its value ranges from 0 (no similarity) to 1 (maximum similarity).

\section{ASSOCIATED CONTENT}

\section{Supporting Information}

The Supporting Information is available free of charge on the ACS Publications website at DOI: 10.1021/acsomega.8b01916.

Mean IR spectra for all single components and binary mixtures; wavenumber assignment derived from PCALDA models for all contaminants varying concentration; Spearman's correlation coefficient and $p$-value for comparing all expected and observed binary mixture spectra for Mallard cells; CYP1A1 protein band intensity assessed by Western blot in MCF-7 and mallard cells induced by treatment with binary mixtures and single contaminants; and Western blotting methodology (PDF) 


\section{AUTHOR INFORMATION}

\section{Corresponding Author}

*E-mail: flmartin@uclan.ac.uk.

\section{ORCID $\odot$}

Francis L. Martin: 0000-0001-8562-4944

\section{Notes}

The authors declare no competing financial interest.

\section{ACKNOWLEDGMENTS}

The authors thank Dr. James M. Harper of Sam Houston State University who generously provided the Mallard fibroblasts. C.L.M.M. acknowledges CAPES-Brazil (grant 88881.128982/ 2016-01) for financial support. The authors thank Dr. Kelly A. Heys for her contribution to the original work. A Natural Environment Research Council (NERC)-CEH funded $\mathrm{PhD}$ studentship funded the original work.

\section{REFERENCES}

(1) Gobas, F. A.; de Wolf, W.; Burkhard, L. P.; Verbruggen, E.; Plotzke, K. Revisiting bioaccumulation criteria for POPs and PBT assessments. Integr. Environ. Assess. Manage. 2009, 5, 624-637.

(2) Samanta, S. K.; Singh, O. V.; Jain, R. K. Polycyclic aromatic hydrocarbons: Environ. Pollut. and bioremediation. Trends Biotechnol. 2002, 20, 243-248.

(3) Sinha, R.; Kulldorff, M.; Gunter, M. J.; Strickland, P.; Rothman, $\mathrm{N}$. Dietary benzo [a] pyrene intake and risk of colorectal adenoma. Cancer Epidemiol., Biomarkers Prev. 2005, 14, 2030-2034.

(4) Rojas, M.; Cascorbi, I.; Alexandrov, K.; Kriek, E.; Auburtin, G.; Mayer, L.; Kopp-Schneider, A.; Roots, I.; Bartsch, H. Modulation of benzo [a] pyrene diolepoxide-DNA adduct levels in human white blood cells by CYP1A1, GSTM1 and GSTT1 polymorphism. Carcinogenesis 2000, 21, 35-41.

(5) Cella, M.; Colonna, M. Aryl hydrocarbon receptor: Linking environment to immunity. Semin. Immunol. 2015, 310-314.

(6) Peters, A. K.; Nijmeijer, S.; Gradin, K.; Backlund, M.; Bergman, Å.; Poellinger, L.; Denison, M.; Van den Berg, M. Interactions of polybrominated diphenyl ethers with the aryl hydrocarbon receptor pathway. Toxicol. Sci. 2006, 92, 133-142.

(7) Hestermann, E. V.; Stegeman, J. J.; Hahn, M. E. Relative contributions of affinity and intrinsic efficacy to aryl hydrocarbon receptor ligand potency. Toxicol. Appl. Pharmacol. 2000, 168, 160172.

(8) Talsness, C. E. Overview of toxicological aspects of polybrominated diphenyl ethers: a flame-retardant additive in several consumer products. Environ. Res. 2008, 108, 158-167.

(9) Dingemans, M. M.; van den Berg, M.; Westerink, R. H. Neurotoxicity of brominated flame retardants:(in) direct effects of parent and hydroxylated polybrominated diphenyl ethers on the(developing) nervous system. Environ. Health Perspect. 2011, 119, 900-907.

(10) Liu, J.; Lewis, G. Environmental toxicity and poor cognitive outcomes in children and adults. J. Environ. Health 2014, 76, 130.

(11) Lammel, G.; Audy, O.; Besis, A.; Efstathiou, C.; Eleftheriadis, K.; Kohoutek, J.; Kukučka, P.; Mulder, M. D.; Přibylová, P.; Prokeš, R. Air and seawater pollution and air-sea gas exchange of persistent toxic substances in the Aegean Sea: spatial trends of PAHs, PCBs, OCPs and PBDEs. Environ. Sci. Pollut. Res. 2015, 1-13.

(12) Crosse, J. D.; Shore, R. F.; Wadsworth, R. A.; Jones, K. C.; Pereira, M. G. $r$ Long-term trends in PBDEs in sparrowhawk (Accipiter nisus) eggs indicate sustained contamination of UK terrestrial ecosystems. Environ. Sci. Technol. 2012, 46, 13504-13511.

(13) Hassanin, A.; Breivik, K.; Meijer, S. N.; Steinnes, E.; Thomas, G. O.; Jones, K. C. PBDEs in European background soils: levels and factors controlling their distribution. Environ. Sci. Technol. 2004, 38, $738-745$.
(14) Loewe, S. Effect of combinations: mathematical basis of problem. Arch. Exp. Pathol. Pharmakol. 1926, 114, 313-326.

(15) Bliss, C. I. The toxicity of poisons applied jointly. Ann. Appl. Biol. 1939, 26, 585-615.

(16) Kortenkamp, A. Ten years of mixing cocktails: a review of combination effects of endocrine-disrupting chemicals. Environ. Health Perspect. 2007, 115, 98.

(17) Kortenkamp, A.; Backhaus, T.; Faust, M. State of the art report on mixture toxicity. Contract 2009, 70307, No. 2007485103.

(18) Shen, W. J.; Hsieh, C. Y.; Chen, C. L.; Yang, K. C.; Ma, C. T.; Choi, P. C.; Lin, C. F. A modified fixed staining method for the simultaneous measurement of reactive oxygen species and oxidative responses. Biochem. Biophys. Res. Commun. 2013, 430, 442-447.

(19) Reits, E. A. J.; Neefjes, J. J. From fixed to FRAP: measuring protein mobility and activity in living cells. Nat. Cell Biol. 2001, 3, E145-E147.

(20) Niapour, M.; Berger, S. Flow cytometric measurement of calpain activity in living cells. Cytometry, Part A 2007, 71, 475-485.

(21) Low, B. W.; Richards, F. M. Measurements of the Density, Composition and Related Unit Cell Dimensions of Some Protein Crystals. J. Am. Chem. Soc. 1954, 76, 2511-2518.

(22) Aoyagi, H.; Yokoi, H.; Tanaka, H. Measurement of fresh and dry densities of suspended plant cells and estimation of their water content. J. Ferment. Bioeng. 1992, 73, 490-496.

(23) O'Otoole, D. K. Weighing Technique for Determining Bacterial Dry Mass Based on Rate of Moisture Uptake. Appl. Environ. Microbiol. 1983, 46, 506-508.

(24) Russell, J. N.; Clements, J. E.; Gama, L. Quantitation of Gene Expression in Formaldehyde-Fixed and Fluorescence-Activated Sorted Cells. PLoS One 2013, 8, No. e73849.

(25) Quinn-Hosey, K. M.; Roche, J. J.; Fogarty, A. M.; Brougham, C. A. Screening for Genotoxicity and Oestrogenicity of Endocrine Disrupting Chemicals in Vitro. J. Environ. Prot. 2012, 3, 902.

(26) Soto, A. M.; Sonnenschein, C.; Chung, K. L.; Fernandez, M. L.; Olea, N.; Serrano, F. O. The E-SCREEN assay as a tool to identify estrogens: an update on estrogenic environmental pollutants. Environ. Health Perspect. 1995, 103, 113-122.

(27) Routledge, E. J.; Sumpter, J. P. Estrogenic activity of surfactants and some of their degradation products assessed using a recombinant yeast screen. Environ. Toxicol. Chem. 1996, 15, 241-248.

(28) Mortelmans, K.; Zeiger, E. The Ames Salmonella/microsome mutagenicity assay. Mutat. Res. 2000, 455, 29-60.

(29) Fenech, M. The cytokinesis-block micronucleus technique: a detailed description of the method and its application to genotoxicity studies in human populations. Mutat. Res. 1993, 285, 35-44.

(30) Singh, N. P.; McCoy, M. T.; Tice, R. R.; Schneider, E. L. A simple technique for quantitation of low levels of DNA damage in individual cells. Exp. Cell Res. 1988, 175, 184-191.

(31) Helm, J. S.; Nishioka, M.; Brody, J. G.; Rudel, R. A.; Dodson, R. E. Measurement of endocrine disrupting and asthma-associated chemicals in hair products used by Black women. Environ. Res. 2018, 165, 448-458.

(32) Sanfilippo, K.; Pinto, B.; Colombini, M. P.; Bartolucci, U.; Reali, D. Determination of trace endocrine disruptors in ultrapure water for laboratory use by the yeast estrogen screen (YES) and chemical analysis (GC/MS). J. Chromatogr. B 2010, 878, 1190-1194.

(33) Rodríguez-Gómez, R.; Zafra-Gómez, A.; Camino-Sánchez, F. J.; Ballesteros, O.; Navalón, A. Gas chromatography and ultra high performance liquid chromatography tandem mass spectrometry methods for the determination of selected endocrine disrupting chemicals in human breast milk after stir-bar sorptive extraction. J. Chromatogr. A 2014, 1349, 69-79.

(34) Benijts, T.; Dams, R.; Lambert, W.; De Leenheer, A. Countering matrix effects in environmental liquid chromatographyelectrospray ionization tandem mass spectrometry water analysis for endocrine disrupting chemicals. J. Chromatogr. A 2004, 1029, 153159.

(35) Wooding, M.; Rohwer, E. R.; Naudé, Y. Determination of endocrine disrupting chemicals and antiretroviral compounds in 
surface water: A disposable sorptive sampler with comprehensive gas chromatography - Time-of-flight mass spectrometry and large volume injection with ultra-high performance liquid chromatography-tandem mass spectrometry. J. Chromatogr. A 2017, 1496, 122132.

(36) Müller, D. J.; Dufrêne, Y. F. Atomic force microscopy: a nanoscopic window on the cell surface. Trends Cell Biol. 2011, 21, 461-469.

(37) Weyn, B.; Kalle, W.; Kumar-Singh, S.; Van Marck, E.; Tanke, H.; Jacob, W. Atomic force microscopy: influence of air drying and fixation on the morphology and viscoelasticity of cultured cells. J. Microsc. 1998, 189, 172-180.

(38) Gavara, N. A beginner's guide to atomic force microscopy probing for cell mechanics. Microsc. Res. Tech. 2017, 80, 75-84.

(39) Kuznetsova, T. G.; Starodubtseva, M. N.; Yegorenkov, N. I.; Chizhik, S. A.; Zhdanov, R. I. Atomic force microscopy probing of cell elasticity. Micron 2007, 38, 824-833.

(40) Hands, J. R.; Abel, P.; Ashton, K.; Dawson, T.; Davis, C.; Lea, R. W.; McIntosh, A. J.; Baker, M. J. Investigating the rapid diagnosis of gliomas from serum samples using infrared spectroscopy and cytokine and angiogenesis factors. Anal. Bioanal. Chem. 2013, 405, $7347-7355$

(41) Theophilou, G.; Lima, K. M.; Martin-Hirsch, P. L.; Stringfellow, H. F.; Martin, F. L. ATR-FTIR spectroscopy coupled with chemometric analysis discriminates normal, borderline and malignant ovarian tissue: classifying subtypes of human cancer. Analyst 2016, 141, 585-594.

(42) Obinaju, B. E.; Alaoma, A.; Martin, F. L. Novel sensor technologies towards environmental health monitoring in urban environments: A case study in the Niger Delta (Nigeria). Environ. Pollut. 2014, 192, 222-231.

(43) Wood, B. R.; Heraud, P.; Stojkovic, S.; Morrison, D.; Beardall, J.; McNaughton, D. A portable Raman acoustic levitation spectroscopic system for the identification and environmental monitoring of algal cells. Anal. Chem. 2005, 77, 4955-4961.

(44) Oca, M. L.; Ortiz, M.; Sarabia, L.; Gredilla, A.; Delgado, D. Prediction of Zamorano cheese quality by near-infrared spectroscopy assessing false non-compliance and false compliance at minimum permitted limits stated by designation of origin regulations. Talanta 2012, 99, 558-565.

(45) Harz, M.; Rösch, P.; Popp, J. Vibrational spectroscopy-A powerful tool for the rapid identification of microbial cells at the single-cell level. Cytometry, Part A 2009, 75, 104-113.

(46) Baker, M. J.; Trevisan, J.; Bassan, P.; Bhargava, R.; Butler, H. J.; Dorling, K. M.; Fielden, P. R.; Fogarty, S. W.; Fullwood, N. J.; Heys, K. A.; Hughes, C.; Lasch, P.; Martin-Hirsch, P. L.; Obinaju, B.; Sockalingum, G. D.; Sulé-Suso, J.; Strong, R. J.; Walsh, M. J.; Wood, B. R.; Gardner, P.; Martin, F. L. Using Fourier transform IR spectroscopy to analyze biological materials. Nat. Protoc. 2014, 9, $1771-1791$

(47) Butler, H. J.; Ashton, L.; Bird, B.; Cinque, G.; Curtis, K.; Dorney, J.; Esmonde-White, K.; Fullwood, N. J.; Gardner, B.; MartinHirsch, P. L.; Walsh, M. J.; McAinsh, M. R.; Stone, N.; Martin, F. L. Using Raman spectroscopy to characterize biological materials. Nat. Protoc. 2016, 11, 664-687.

(48) Martin, F. L.; Kelly, J. G.; Llabjani, V.; Martin-Hirsch, P. L.; Patel, I. I.; Trevisan, J.; Fullwood, N. J.; Walsh, M. J. Distinguishing cell types or populations based on the computational analysis of their infrared spectra. Nat. Protoc. 2010, 5, 1748-1760.

(49) Matthäus, C.; Bird, B.; Miljković, M.; Chernenko, T.; Romeo, M.; Diem, M. Chapter 10 Infrared and Raman Microscopy in Cell Biology. Methods Cell Biol. 2008, 89, 275-308.

(50) Sinjab, F.; Sicilia, G.; Shipp, D. W.; Marlow, M.; Notingher, I. Label-Free Raman Hyperspectral Imaging of Single Cells Cultured on Polymer Substrates. Appl. Spectrosc. 2017, 71, 2595-2607.

(51) Yang, S.; Dai, X.; Stogin, B. B.; Wong, T. -S Ultrasensitive surface-enhanced Raman scattering detection in common fluids. Proc. Natl. Acad. Sci. USA 2016, 113, 268-273.
(52) Hobro, A. J.; Smith, N. I. An evaluation of fixation methods: Spatial and compositional cellular changes observed by Raman imaging. Vib. Spectrosc. 2017, 91, 31-45.

(53) Rindzevicius, T.; Barten, J.; Vorobiev, M.; Schmidt, M. S.; Castillo, J. J.; Boisen, A. Detection of surface-linked polychlorinated biphenyls using surface-enhanced Raman scattering spectroscopy. Vib. Spectrosc. 2017, 90, 1-6.

(54) Jiang, X.; Lai, Y.; Wang, W.; Jiang, W.; Zhan, J. Surfaceenhanced Raman spectroscopy detection of polybrominated diphenylethers using a portable Raman spectrometer. Talanta 2013, 116, 14-17.

(55) Kelly, J. G.; Trevisan, J.; Scott, A. D.; Carmichael, P. L.; Pollock, H. M.; Martin-Hirsch, P. L.; Martin, F. L. Biospectroscopy to metabolically profile biomolecular structure: a multistage approach linking computational analysis with biomarkers. J. Proteome Res. 2011, 10, 1437-1448.

(56) Obinaju, B. E.; Graf, C.; Halsall, C.; Martin, F. L. Linking biochemical perturbations in tissues of the African catfish to the presence of polycyclic aromatic hydrocarbons in Ovia River, Niger Delta region. Environ. Pollut. 2015, 201, 42-49.

(57) Llabjani, V.; Trevisan, J.; Jones, K. C.; Shore, R. F.; Martin, F. L. Binary mixture effects by PBDE congeners (47, 153, 183, or 209) and PCB congeners (126 or 153) in MCF-7 cells: biochemical alterations assessed by IR spectroscopy and multivariate analysis. Environ. Sci. Technol. 2010, 44, 3992-3998.

(58) Oberreuter, H.; Martens, F.; Seiler, H.; Scherer, S. Quantification of micro-organisms in binary mixed populations by Fourier transform infrared (FT-IR) spectroscopy. Lett. Appl. Microbiol. 2000, 30, 85-89.

(59) Wehbe, K.; Vezzalini, M.; Cinque, G. Detection of mycoplasma in contaminated mammalian cell culture using FTIR microspectroscopy. Anal. Bioanal. Chem. 2018, 410, 3003-3016.

(60) Movasaghi, Z.; Rehman, S.; ur Rehman, D. I. Fourier transform infrared (FTIR) spectroscopy of biological tissues. Appl. Spectrosc. Rev. 2008, 43, 134-179.

(61) Luch, A. Nature and nurture-lessons from chemical carcinogenesis. Nat. Rev. Cancer 2005, 5, 113-125.

(62) Hockley, S. L.; Arlt, V. M.; Brewer, D.; Giddings, I.; Phillips, D. $\mathrm{H}$. Time- and concentration-dependent changes in gene expression induced by benzo(a)pyrene in two human cell lines, MCF-7 and HepG2. BMC Genomics 2006, 7, 260.

(63) Hirano, M.; Hwang, J.-H.; Park, H.-J.; Bak, S.-M.; Iwata, H.; Kim, E.-Y. In Silico Analysis of the Interaction of Avian Aryl Hydrocarbon Receptors and Dioxins to Decipher Isoform-, Ligand-, and Species-Specific Activations. Environ. Sci. Technol. 2015, 49, 3795-3804.

(64) Burchiel, S. W.; Thompson, T. A.; Lauer, F. T.; Oprea, T. I. Activation of dioxin response element (DRE)-associated genes by benzo (a) pyrene 3, 6-quinone and benzo (a) pyrene 1, 6-quinone in MCF-10A human mammary epithelial cells. Toxicol. Appl. Pharmacol. 2007, 221, 203-214.

(65) Yan, C.; Wu, W.; Li, H.; Zhang, G.; Duerksen-Hughes, P. J.; Zhu, X.; Yang, J. Benzo [a] pyrene treatment leads to changes in nuclear protein expression and alternative splicing. Mutation Res. 2010, 686, 47-56.

(66) Viberg, H.; Fredriksson, A.; Eriksson, P. Investigations of strain and/or gender differences in developmental neurotoxic effects of polybrominated diphenyl ethers in mice. Toxicol. Sci. 2004, 81, 344353.

(67) He, P.; Wang, A.-G.; Xia, T.; Gao, P.; Niu, Q.; Guo, L.-J.; Xu, B.-Y.; Chen, X.-M. Mechanism of the neurotoxic effect of PBDE-47 and interaction of PBDE-47 and PCB153 in enhancing toxicity in SHSY5Y cells. Neurotoxicology 2009, 30, 10-15.

(68) Pellacani, C.; Buschini, A.; Galati, S.; Mussi, F.; Franzoni, S.; Costa, L. G. Evaluation of DNA damage induced by 2 polybrominated diphenyl ether flame retardants (BDE-47 and BDE209) in SK-N-MC cells. Int. J. Toxicol. 2012, 31, 372-379. 
(69) Li, M.; Liu, Z.; Gu, L.; Yin, R.; Li, H.; Zhang, X.; Cao, T.; Jiang, C. Toxic effects of decabromodiphenyl ether (BDE-209) on human embryonic kidney cells. Front. Genet. 2014, 5, No. 118.

(70) Diamond, M. P.; Wirth, J. J.; Saed, G. M. PCBs enhance collagen I expression from human peritoneal fibroblasts. Fertil. Steril. 2008, 90, 1372-1375.

(71) Al-Salman, F.; Plant, N. Non-coplanar polychlorinated biphenyls (PCBs) are direct agonists for the human pregnane-X receptor and constitutive androstane receptor, and activate target gene expression in a tissue-specific manner. Toxicol. Appl. Pharmacol. 2012, $263,7-13$.

(72) Cedergreen, N. Quantifying synergy: a systematic review of mixture toxicity studies within environmental toxicology. PLoS One 2014, 9, No. e96580.

(73) Hu, L.-X.; Ying, G.-G.; Chen, X.-W.; Huang, G.-Y.; Liu, Y.-S.; Jiang, Y.-X.; Pan, C.-G.; Tian, F.; Martin, F. L. FTIR spectroscopy as a novel approach towards providing effect-based endpoints in duckweed toxicity testing. Environ. Toxicol. Chem. 2017, 36, 346.

(74) Darnerud, P. O.; Eriksen, G. S.; Jóhannesson, T.; Larsen, P. B.; Viluksela, M. Polybrominated diphenyl ethers: occurrence, dietary exposure, and toxicology. Environ. Health Perspect. 2001, 109, 49.

(75) Bemis, J. C.; Nazarenko, D. A.; Gasiewicz, T. A. Coplanar polychlorinated biphenyls activate the aryl hydrocarbon receptor in developing tissues of two TCDD-responsive lacZ mouse lines. Toxicol. Sci. 2005, 87, 529-536.

(76) Courter, L. A.; Pereira, C.; Baird, W. M. Diesel exhaust influences carcinogenic PAH-induced genotoxicity and gene expression in human breast epithelial cells in culture. Mutat. Res. 2007, $625,72-82$

(77) Tarantini, A.; Maître, A.; Lefèbvre, E.; Marques, M.; Rajhi, A.; Douki, T. Polycyclic aromatic hydrocarbons in binary mixtures modulate the efficiency of benzo [a] pyrene to form DNA adducts in human cells. Toxicology 2011, 279, 36-44.

(78) Mundy, W. R.; Freudenrich, T. M.; Crofton, K. M.; DeVito, M. J. Accumulation of PBDE-47 in Primary Cultures of Rat Neocortical Cells. Toxicol. Sci. 2004, 82, 164-169.

(79) Ghosh, S.; De, S.; Chen, Y.; Sutton, D. C.; Ayorinde, F. O.; Dutta, S. K. Polychlorinated biphenyls (PCB-153) and (PCB-77) absorption in human liver (HepG2) and kidney (HK2) cells in vitro: PCB levels and cell death. Environ. Int. 2010, 36, 893-900.

(80) Costa, L. G.; de Laat, R.; Tagliaferri, S.; Pellacani, C. A mechanistic view of polybrominated diphenyl ether (PBDE) developmental neurotoxicity. Toxicol. Lett. 2014, 230, 282-294.

(81) Madureira, D. J.; Weiss, F. T.; Van Midwoud, P.; Helbling, D. E.; Sturla, S. J.; Schirmer, K. Systems Toxicology Approach to Understand the Kinetics of Benzo(a)pyrene Uptake, Biotransformation, and DNA Adduct Formation in a Liver Cell Model. Chem. Res. Toxicol. 2014, 27, 443-453.

(82) Fertmann, R.; Tesseraux, I.; Schümann, M.; Neus, H. Evaluation of ambient air concentrations of polycyclic aromatic hydrocarbons in Germany from 1990 to 1998. J. Exposure Sci. Environ. Epidemiol. 2002, 12, 115-123.

(83) Beebe, K. R.; Pell, R. J.; Seasholtz, M. B. Chemometrics: A Practical Guide; New York: John Wiley \& Sons, 1998.

(84) Ballabio, D.; Consonni, V. Classification tools in chemistry. Part 1: linear models. PLS-DA. Anal. Methods 2013, 5, 3790-3798.

(85) Bro, R.; Smilde, A. K. Principal component analysis. Anal. Methods 2014, 6, 2812-2831.

(86) Morais, C. L. M.; Lima, K. M. G. Principal Component Analysis with Linear and Quadratic Discriminant Analysis for Identification of Cancer Samples Based on Mass Spectrometry. J. Braz. Chem. Soc. 2018, 29, 472-481.

(87) Dixon, S. J.; Brereton, R. G. Comparison of performance of five common classifiers represented as boundary methods: Euclidean Distance to Centroids, Linear Discriminant Analysis, Quadratic Discriminant Analysis, Learning Vector Quantization and Support Vector Machines, as dependent on data structure. Chemom. Intell. Lab. Syst. 2009, 95, 1-17.
(88) Siqueira, L. F.; Lima, K. M. G. MIR-biospectroscopy coupled with chemometrics in cancer studies. Analyst 2016, 141, 4833-4847. (89) Wu, W.; Mallet, Y.; Walczak, B.; Penninckx, W.; Massart, D. L.; Heuerding, S.; Erni, F. Comparison of regularized discriminant analysis, linear discriminant analysis and quadratic discriminant analysis, applied to NIR data. Anal. Chim. Acta 1996, 329, 257-265. 